\title{
Direct molecular dissection of tumor parenchyma from tumor stroma in tumor xenograft using mass spectrometry-based glycoproteomics
}

\author{
Xiaoying Ye ${ }^{1}$, Brian T. Luke ${ }^{2}$, Bih-Rong $\mathbf{W e i}^{3}$, Jan A. Kaczmarczyk ${ }^{4}$, Jadranka \\ Loncarek ${ }^{5}$, Jennifer E. Dwyer ${ }^{3}$, Donald J. Johann ${ }^{6}$, Richard G. Saul ${ }^{4}$, Dwight V. \\ Nissley $^{1}$, Frank McCormick ${ }^{7}$, Gordon R. Whiteley ${ }^{1}$ and Josip Blonder ${ }^{1}$ \\ ${ }^{1}$ National Cancer Institute RAS Initiative, Cancer Research Technology Program, Frederick National Laboratory for Cancer \\ Research, Leidos Biomedical Research, Inc., Frederick, MD 21702, USA \\ ${ }^{2}$ Advanced Biomedical Computing Center, Frederick National Laboratory for Cancer Research, Leidos Biomedical Research, \\ Inc., Frederick, MD 21702, USA \\ ${ }^{3}$ Laboratory of Cancer Biology and Genetics, Center for Cancer Research, National Cancer Institute, Bethesda, MD 20892, \\ USA \\ ${ }^{4}$ Cancer Research Technology Program, Antibody Characterization Laboratory, Frederick National Laboratory for Cancer \\ Research, Leidos Biomedical Research, Inc., Frederick, MD 21702, USA \\ ${ }^{5}$ Laboratory of Protein Dynamics and Signaling, Center for Cancer Research, National Cancer Institute, Frederick, MD 21702, \\ USA \\ ${ }^{6}$ Winthrop P. Rockefeller Cancer Institute, University of Arkansas for Medical Sciences, Little Rock, AR 72209, USA \\ ${ }^{7}$ UCSF Helen Diller Family Comprehensive Cancer Center, San Francisco, CA 94158, USA \\ Correspondence to: Josip Blonder, email: blonderj@mail.nih.gov
}

Keywords: lung cancer; tumor microenvironment

Received: March 22, $2018 \quad$ Accepted: May 02, $2018 \quad$ Published: May 29, 2018

Copyright: Ye et al. This is an open-access article distributed under the terms of the Creative Commons Attribution License 3.0 (CC BY 3.0), which permits unrestricted use, distribution, and reproduction in any medium, provided the original author and source are credited.

\section{ABSTRACT}

The most widely used cancer animal model is the human-murine tumor xenograft. Unbiased molecular dissection of tumor parenchyma versus stroma in human-murine xenografts is critical for elucidating dysregulated protein networks/pathways and developing therapeutics that may target these two functionally codependent compartments. Although antibody-reliant technologies (e.g., immunohistochemistry, imaging mass cytometry) are capable of distinguishing tumor-proper versus stromal proteins, the breadth or extent of targets is limited. Here, we report an antibodyfree targeted cross-species glycoproteomic (TCSG) approach that enables direct dissection of human tumor parenchyma from murine tumor stroma at the molecular/ protein level in tumor xenografts at a selectivity rate presently unattainable by other means. This approach was used to segment/dissect and obtain the protein complement phenotype of the tumor stroma and parenchyma of the metastatic human lung adenocarcinoma A549 xenograft, with no need for tissue microdissection prior to mass-spectrometry analysis. An extensive molecular map of the tumor proper and the associated microenvironment was generated along with the top functional $\mathbf{N}$-glycosylated protein networks enriched in each compartment. Importantly, immunohistochemistry-based cross-validation of selected parenchymal and stromal targets applied on human tissue samples of lung adenocarcinoma and normal adjacent tissue is indicative of a noteworthy translational capacity for this unique approach that may facilitate identifications of novel targets for next generation antibody therapies and development of real time preclinical tumor models. 


\section{INTRODUCTION}

Adherent two-dimensionally (2D) cultured human cancer cells are a widely used model system in cancer research and drug screening [1]. However, the biological relevance of results obtained using in vitro $2 \mathrm{D}$-cultured cancer cell models is constrained by the lack of a natural tumor microenvironment (i.e., stroma) that provides a genuine proliferative cellular background via paracrine signals and metabolic gradients, which are fundamental and necessary for recapitulating tumor development and metastasis [2]. Hence, numerous murine xenograft models have been developed to study solid tumors in native tissue environments and to further substantiate the biology observed using 2D-cultured cancer cell lines [3].

Histologically speaking, tumor xenografts have a microanatomic configuration analogous to common solid tumors. These are characterized by the existence of two morphologically well-defined and functionally interdependent compartments: i) the parenchyma, comprising neoplastic tumor cells of diverging morphology, antigenicity, and metastatic capacity, and ii) the stroma, comprising different cellular elements including tumor fibroblasts, endothelial cells, and immune cells [4]. In human-murine tumor xenografts, the stroma is principally a product of the host (i.e., mouse), while the parenchyma consists of grafted neoplastic cells (e.g., human tumors or cell lines) [5]. During tumorigenesis, parenchymal neoplastic tumor cells secrete cytokines, growth factors, and proteolytic enzymes to sustain their survival and induce and/or modify the tumor stroma formation [6]. In this regard, any solid tumor bigger than two millimeters in diameter must induce its own blood supply, since it cannot survive without a stroma that provides a vascular network for nutrient supply and waste removal [7].

Historically, a tumor cell-centric view of cancer enabled a better understanding of tumorigenesis and facilitated the development of drugs that directly targeted tumor cells (i.e., parenchyma) using small molecules [8] or biologicals [9]. Yet, recent research efforts focused on the tumor microenvironment have shown that the tumor stroma is a legitimate anti-cancer target [10]. Consequently, the ability to analyze and differentiate tumor parenchyma from tumor stroma at the molecular level in tumor xenografts is critical for better understanding cancer biology and discovering novel and more-effective drugs/treatments that target both tumor and stroma compartments in a concurrent manner [2].

A variety of antibody-reliant technologies (e.g., immunohistochemistry, imaging mass cytometry) can be used to ascertain direct topographic distinctions between tumor parenchyma and stroma but only for a limited number of previously selected protein targets [11-13]. State-of-the-art mass spectrometry (MS)-based, antibody-free profiling of targeted tumor sections/cells relies primarily on laser capture microdissection (LCM) [14] for collecting histologically homogenous cell populations (e.g., neoplastic cells, stromal cells) prior to liquid chromatography (LC-MS)-based proteomic analysis $[15,16]$. While the functional linkage between LCM and LC-MS-based proteomics enables the identification of hundreds of endogenous protein species [17-19], the optical resolution may potentially limit LCM and make the isolation of homogeneous cell populations more challenging [15]. In addition, the cost of the LCM apparatus and the obligatory requirement for a pathologist or technologist familiar with the identification/selection of targeted cells represent additional requirements [20].

Alternately, shotgun proteomics may be employed $[21,22]$. However, its utility is greatly restricted due to a remarkably low dissimilarity rate (i.e., $40 \%$ ) between the human and mouse MS-identifiable peptidome/proteome, which leads to exceedingly high rates of removal of peptide/ protein identifications $[21,22]$. This is because $60 \%$ of mouse and human MS-identifiable plain, unmodified tryptic peptides are identical (i.e., they share the same sequence). With a species specificity attribute lacking [23], MS-based discovery of viable drug targets and/or relevant biomarkers has proven to be a challenging task.

Described in this study is an antibody-free targeted cross-species N-glycoproteomic (TCSG) approach that allows for direct virtual molecular dissection/differentiation of the mouse- derived tumor microenvironment (i.e., tumor stroma) from the humanderived malignant cells (i.e., tumor parenchyma). This is performed in murine tumor xenografts at an acquisition rate presently unattainable by other means. TCSG utilizes our discovery, which showed for the first time a much higher amino acid (AA) sequence dissimilarity rate between the human and mouse MS-identifiable $\mathrm{N}$-glycopeptidome compared to the corresponding plain human and mouse MS-identifiable unmodified tryptic peptidome.

To demonstrate our discovery, we adapted hydrazidebased glycoproteomics [24] to a TCSG-based proteomewide dissection of tumor stroma from tumor parenchyma and applied it on an A549 metastatic lung adenocarcinoma tumor xenograft model. Using TCSG, we generated an extensive molecular map of the stromal and parenchymal proteome and observed unprecedented selectivity and sensitivity when differentiating tumor stroma from tumor parenchyma at the protein level. We also mapped and cross-validated the top $\mathrm{N}$-glycoprotein networks activated in these two distinct co-dependent tumor compartments. The translational relevance of TCSG was confirmed by immunohistochemical (IHC) cross-validation. Here, selected parenchymal and stromal targets in matching human lung adenocarcinoma revealed a positive correlation in their location and expression compared to results obtained by TCSG in a murine lung adenocarcinoma xenograft model. 


\section{RESULTS}

\section{In silico computation revealed an exceedingly larger cross-species divergence/dissimilarity between the MS-identifiable $\mathrm{N}$-glycosylated peptidome and the plain, unmodified peptidome}

In human-murine tumor xenografts, the parenchymal proteome is a product of the human neoplastic tumor cells, while the stromal proteome is principally a product of the host's (i.e., mouse) tumor microenvironment [25]. Based on the critical role played by protein glycosylation in cancer biology [26] and self/nonself immune recognition [27], we hypothesized that the difference and/or dissimilarity rate between the human (parenchyma) and mouse (stroma) $\mathrm{N}$-glycopeptidome/proteome ought to be substantially larger than the actual dissimilarity rate between the corresponding ordinary human/mouse MS-identifiable unmodified peptidome/proteome. To test our hypothesis, we performed a comparative analysis of human and mouse MS-identifiable N-glycosylated peptidome (from six AAs to 35 AAs long) in silico targeting the N-X-S|T motif in full protein sequences to estimate and compare differences in AA sequences between the modified MS-identifiable N-glycopeptidome and the plain MSidentifiable unmodified tryptic peptidome. The results of this in silico analysis showed that $75.7 \%$ of the observed mouse MS-identifiable N-glycopeptides containing the N-X-S $\mid \mathrm{T}$ amino-acid motif as well as $69.7 \%$ of the observed human MS-identifiable N-glycopeptides were distributed differently in a protein- and species-specific manner, exhibiting an average glycopeptide dissimilarity rate of $72.7 \%$ (Figure 1, Bar B).

This extensive dissimilarity rate is critical, and it enables direct molecular dissection of the tumor stroma from the tumor parenchyma by relying on speciesspecific differences between the parenchymal humanderived and stromal murine-derived MS-identifiable $\mathrm{N}$-glycopeptidome. Evidently, only $27.3 \%$ of all MSidentifiable $\mathrm{N}$-glycopeptides are shared between the human-derived and mouse-derived N-glycopeptidome, which is in striking contrast to the unmodified MSidentifiable tryptic peptides, which are $60 \%$ shared between the two species [23]. Thus, in any MS-based comparison between the human-derived parenchymal and mouse-derived stromal dataset, $\sim 60 \%$ of identified plain tryptic peptides should be thrown out because they are shared between two species [23], as depicted by a corresponding dissimilarity rate of only $40 \%$ (Figure 1, Bar A). Taken together, our results obtained in silico confirm our hypothesis and are indicative of the unparalleled potential of targeted $\mathrm{N}$-glycoproteomics to enable in-depth dissection of tumor stroma from tumor parenchyma in human-murine tumor xenografts using TCSG.

\section{TCSG analysis of the A549 tumor xenograft recapitulates in silico computed divergence/ dissimilarity between the human and mouse MS- identifiable $\mathrm{N}$-glycopeptidome}

The next step carried out a proof-of-principle study by applying TCSG to analyze/dissect tumor stroma from tumor parenchyma in a metastatic lung adenocarcinoma xenograft model. This was generated by injecting A549 $\left(\mathrm{KRas}^{\mathrm{G}}{ }^{12 \mathrm{~S}}\right)$ human lung adenocarcinoma cells through the tail vein in nude mice as previously described [28]. Concurrently, normal mouse lung tissue collected from age- and gender-matched mice injected with normal saline and in vitro 2D-grown A549 cancer cells served as controls (Figure 2). To take full advantage of our in silico discovery and validate the hypothesis ex vivo, we first adopted and optimized the TCSG workflow (Supplementary Figure 1). The critical steps involved were (i) cryostatfacilitated tissue homogenization [29], (ii) aqueousorganic buffer-facilitated protein solubilization/digestion [30], (iii) N-glycosylated peptides capture [24, 31] using hydrazide-coated magnetic beads, and (iv) highly selective and sensitive cross-species N-glycoproteomic LC-MS analysis.

To ensure reliability and increase coverage, the samples were prepared on three independent occasions/ repeats (i.e., biological replicates). Each sample was injected six times (i.e., technical replicates) into the highresolution/accuracy hybrid MS and raw MS-data collated for further processing. After tissue homogenization and/or cell lysis, tryptic digestion was carried out in a mixed organic-aqueous buffer followed by oxidation of glycosylated peptides along with their covalent capture on hydrazide-coated magnetic beads. Next, nonglycopeptides were removed using stringent washes followed by the PNGase F-mediated release of N-linked glycopeptides, which were then analyzed using highresolution and high mass accuracy LC-MS.

The measured tandem $\left(\mathrm{MS}^{2}\right)$ spectra acquired from the tumor xenograft digestate were collated and searched against both the human and the mouse proteome databases, respectively. The $\mathrm{MS}^{2}$ spectra obtained from normal murine lung tissue were searched against the mouse database, while the $\mathrm{MS}^{2}$ spectra acquired from 2D-grown A549 human cancer cells were searched against the human proteome database. TCSG analysis of the xenograft tissue resulted in the identification of 764 human and 919 mouse $\mathrm{N}$-glycopeptides (Supplementary Table 1A-1B) showing deamidated asparagine shift $(0.984 \mathrm{Da})$ and $\mathrm{N}-\mathrm{X}-\mathrm{S} \mid \mathrm{T}$ amino-acid motif. Correspondingly, a total of 1,263 mouse N-glycosylated peptides (Supplementary Table 2A) were identified in normal murine lungs, and 999 human N-glycosylated peptides (Supplementary Table 2B) were identified in 2D-grown A549 human lung cancer cells.

To evaluate the utility of the TCSG platform and confirm our hypothesis, we set out to compare 


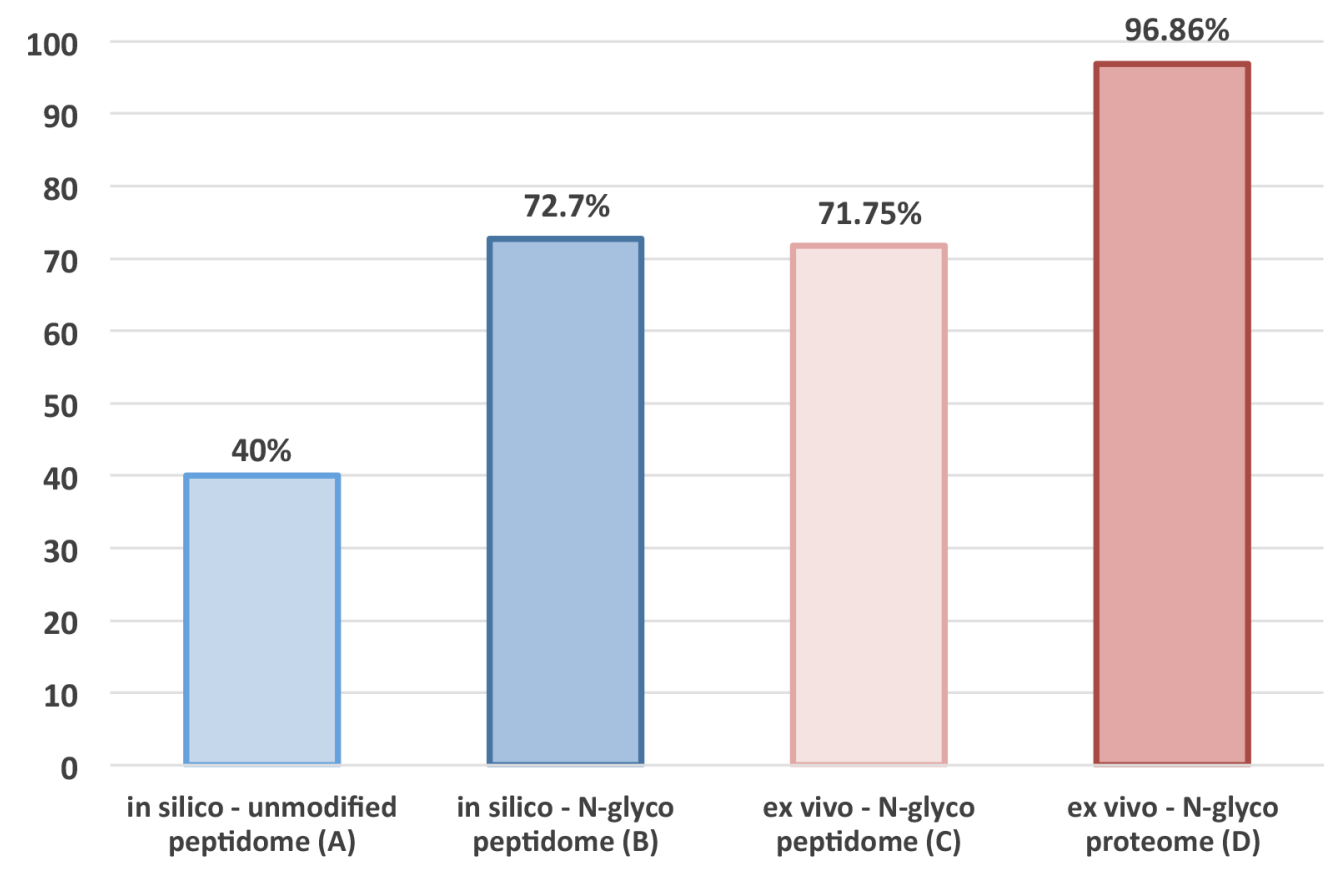

Figure 1: Dissimilarity rate analysis. Results of in silico analysis (Bars A-B) comparing the dissimilarity rate between the human and mouse MS-identifiable plain tryptic peptidome (A) and MS-identifiable N-glycopeptidome, plus results of a corresponding ex vivo analysis (Bars C-D) comparing the observed dissimilarity rate between the human and mouse MS-identifiable N-glycopeptidome and N-glycoproteome.
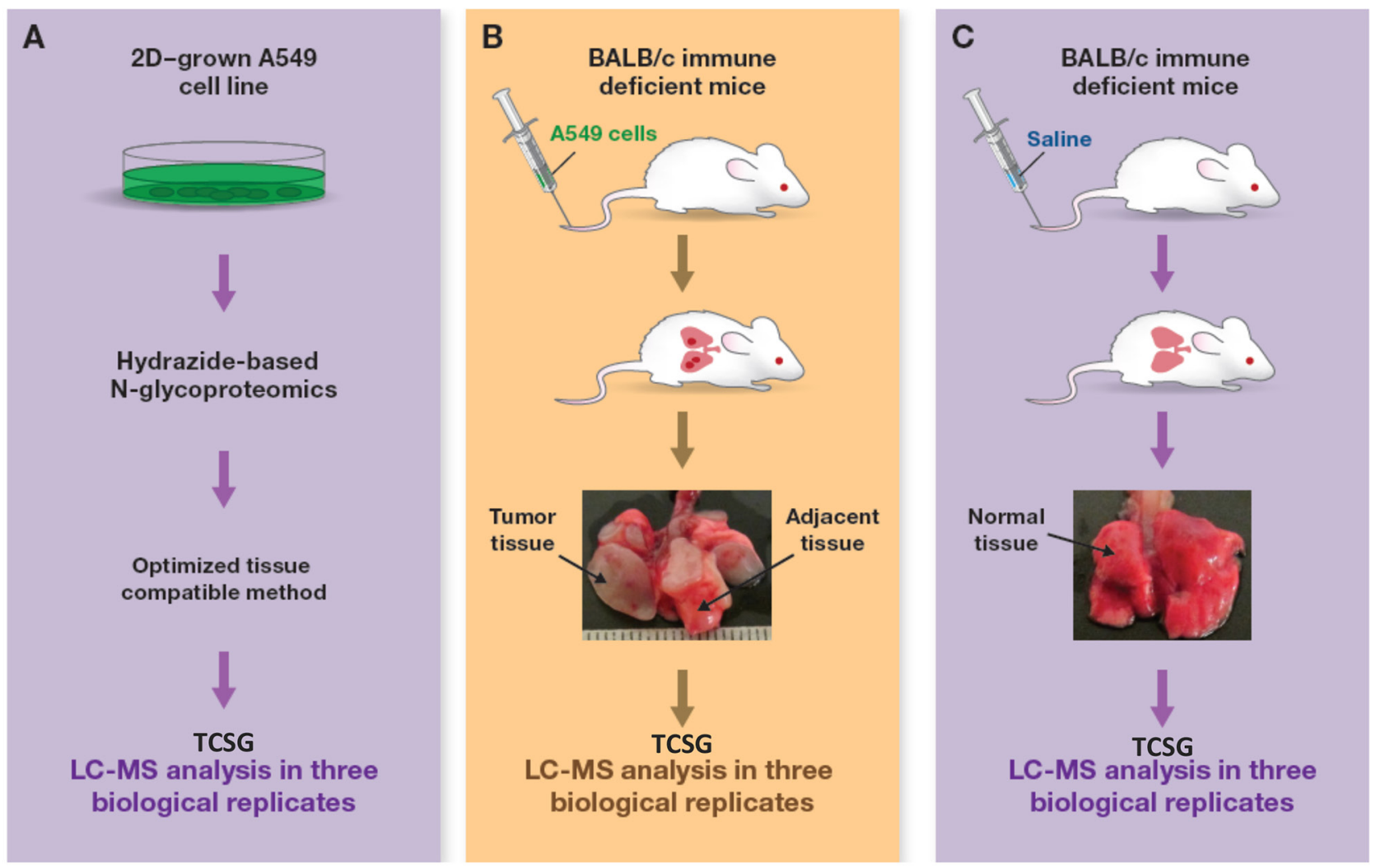

Figure 2: Experimental design and workflow. TCSG-based molecular profiling of (A) tumor xenograft using (B) normal lung tissue and (C) 2D-grown A549 cell lines as controls. 
experimentally observed dissimilarity rates in N-glyco site distributions between the human and mouse $\mathrm{N}$-glycopeptidome. Towards this goal, we combined all identified peptides of human origin detected in tumor xenograft tissue and the A549 human lung cancer cell line in a single file (Supplementary Table 3A). Similarly, all identified peptides of mouse origin detected in the tumor xenograft and normal mouse lungs were combined into another file (Supplementary Table 3B). Then, each full protein sequence from the UniProt mouse proteome database was analyzed to see if it contained any of the observed/identified human N-glycopeptides. Each UniProt human protein sequence was analyzed to see if it contained any of the mouse detected peptides. The analysis revealed that $69.5 \%$ of the observed mouse $\mathrm{N}$-glycosylated peptides containing the N-X-S|T amino-acid motif and $74 \%$ of the observed human $\mathrm{N}$-glycosylated peptides were proteinand species-specific, exhibiting an average dissimilarity rate of $71.75 \%$ (Figure 1, Bar C).

The results of this analysis are in direct agreement with our hypothesis. They confirm the utility of TCSG to capture ex vivo differences between humans and mice via MS-identifiable $\mathrm{N}$-glycopeptidome at the dissimilarity rate predicted in silico. This approach enables a direct virtual dissection of tumor parenchyma from tumor stroma in human-mouse xenografts in a species-specific manner and at a rate previously unattainable by other means. In comparison with other published approaches, the essential distinction and unparalleled selectivity of TCSG is derived directly from our discovery that revealed a much higher cross-species dissimilarity rate between human and mouse N-glycopeptidome compared to the dissimilarity rate between human and mouse plain MS-identifiable unmodified tryptic peptidome.

\section{TCSG enables extensive and highly selective phenotyping of the tumor stroma and tumor parenchyma at the protein level without the need for laser-based microdissection}

Finally, the TCSG analysis resulted in a total of 438 mouse-stromal (Supplementary Table 4A) and 347 parenchymal-human (Supplementary Table 4B) $\mathrm{N}$-glycosylated protein species identified in tumor xenograft. Importantly, a stringent false peptide discovery rate (FDR) cutoff of $\leq 1 \%$ was employed. Here, the acquired $\mathrm{MS}^{2}$ spectra were searched against a non-redundant Swiss-Prot human proteome database containing 20,194 protein sequences and the corresponding non-redundant Swiss-Prot mouse proteome database containing 16,299 protein sequences using the SEQUEST algorithm, which is included within the Protein Discoverer (version 1.4) software suite (Thermo). To further decrease redundancy in protein identification, protein grouping was used to generate a minimum protein list that covers all identified peptides and thereby removes redundant identifications via peptides belonging to multiple protein species. Additionally, glycoproteins identified by a single peptide matching spectrum (PMS) were not included in the final dataset. Correspondingly, a total of 471 mouse and 366 human N-glycosylated proteins were identified in normal mouse tissue and 2D-grown A549 cells, respectively (Supplementary Table 5A-5B).

These stringent searching criteria were employed to determine actual TCSG selectivity in separating/dissecting tumor stroma from tumor parenchyma at the molecular/ protein level. Towards this goal, we analyzed both human and mouse protein datasets/lists to elucidate legitimate human-derived (i.e., parenchymal) from mouse-derived (i.e., stromal) proteins and/or protein groups detected in tumor xenograft. The analysis revealed that out of 438 initially identified mouse proteins and/or protein groups in tumor xenografts, a total of 427 (97.48\%) were identified as genuine stromal proteins by at least a single N-glycosylated peptide in a protein- and species-specific manner (Supplementary Figure 2, Supplementary Table 6A). Correspondingly, from the 347 human proteins identified in tumor xenografts, a total of $334(96.25 \%)$ were identified as genuine parenchymal proteins in a protein- and speciesspecific manner (Supplementary Figure 2, Supplementary Table 6B), corresponding to an average dissimilarity rate of $96.86 \%$ (Figure 1, Bar D). An identical analysis applied to a control normal mouse tissue and an A549 human cancer cell line produced similar results. Namely, 459 out of $472(97.24 \%)$ mouse proteins detected in a normal mouse tissue control and 352 out of 366 proteins $(96.17 \%)$ detected in 2D-grown A549 human lung adenocarcinoma cells (Supplementary Figure 2, Supplementary Table 7A-7B) were identified in a protein- and species-specific manner. These results illustrate the inherent capability of this approach to generate glycopeptide and/or glycoprotein identifications in a protein- and species-dependent manner at a rate currently unattainable by other means. It also provides explicit evidence of an unprecedent TCSG capacity for virtual molecular dissection of tumor stroma from tumor parenchyma in murine tumor xenografts without utilizing laser-based microdissection to obtain homogenous parenchymal/stromal cell populations.

\section{TCSG-based subtractive proteomics reveals stroma-unique mouse-derived and parenchyma- unique human-derived phenotypes}

Raw tumor xenograft LC-MS data obtained by TCSG were searched against the mouse and human proteome databases, respectively. Proteins unique to mouse stroma and human parenchyma identified by at least one species-specific peptide were uncovered by subtracting overlapping protein orthologs from the original datasets. This analysis revealed a total of 211 proteins unique to tumor stroma along with a total of 118 proteins unique to tumor parenchyma (Supplementary Table 8A-8B). Notably, 
out of 211 identified mouse-derived stromal proteins, a total of $110(52.13 \%)$ were annotated as authentic cell surface molecules in the cell surface protein atlas (CSPA) (Supplementary Table 8A) [32]. Of these, a total of 47 $(42.72 \%)$ of the identified cell surface glycoproteins are annotated as cluster of differentiation (CD) molecules [33]. This is indicative of a significantly increased rate of CD molecules identified in tumor stroma. Interestingly, this is in comparison to an overall rate of $2 \%$ that $\mathrm{CD}$ molecules represent within the entire non-redundant SwissProt human/ mouse proteome database. Correspondingly, out of 118 identified human-derived stromal proteins, a total of 48 $(40.67 \%)$ were genuine cell surface molecules found in CSPA [32], of which a total of $15(31.25 \%)$ were classified as CD molecules (Supplementary Table $8 \mathrm{~B}$ ). A significantly increased identification rate of $\mathrm{CD}$ molecules in tumor stroma is consistent with a higher content of immune cells (e.g., leukocytes) found in the tumor microenvironment (e.g., tumor-associated macrophages) and serves as another indicator of TCSG's ability to capture interesting and timely aspects of the phenotype of the tumor microenvironment.

Next, we carried out a multiplex subtractive proteomic analysis by including control samples to elucidate mouse-derived proteins detected exclusively in tumor stroma. These identifications were below the level found in normal lung tissue and without detection of matching human-derived orthologs in tumor parenchyma or 2D-grown A549 cells. Towards this goal, we subtracted overlapping gene products detected in each dataset (e.g., tumor stroma) from the non-redundant list of collated overlapping orthologs detected in three other samples (e.g., tumor parenchyma, 2D-grown A549 cells, and normal murine lungs). This analysis revealed an exclusive detection of protein subsets/panels unique to tumor stroma (40 targets), tumor parenchyma (47 targets), 2D-grown A549 cancer cells (97 targets), and normal lung tissue (91 targets). These may be considered as putative stromal and parenchymal markers/targets critical for the biology of the tumor model under study, and they allow for a better understanding of the biology of 2D-grown A549 cells or normal lung tissue (Supplementary Table 9A-9D).

To assess the utility of multiplex subtractive proteomics, we investigated the biological processes established in the literature and reported for each of the 10 most abundant proteins detected exclusively in tumor stroma, tumor parenchyma, 2D-grown A549 cells, and normal mouse lungs, respectively. Remarkably, each of the 10 most abundant protein species (Table 1) detected exclusively in tumor stroma are known to be involved in immune processes. Of these, transmembrane glycoprotein NMB (Gpnmb), low affinity immunoglobulin gamma Fc region receptor II (Fcgr2), H-2 class I histocompatibility antigen, alpha chain, and programmed cell death 1 ligand 2 (Pded1lg2) are directly involved in tumor immune evasion. Conversely, the clear majority of the 10 most abundant human-derived gene products detected exclusively in tumor parenchyma (e.g., CEACAM5, MUC5B, FCGBP) were found to be involved in metastasis (Table 2). Predictably, the most abundant human-derived protein species detected exclusively in 2D-grown A549 cells (e.g., NTRK3, NRCAM, CTCS, EPHA2) involved cell proliferation (Table 3). Evidently, most of the abundant proteins exclusively detected in normal mouse lungs (Table 4) belong to "housekeeping" protein species (e.g., Abca8a, Lepr, B4gat1, Hyal2). Taken together, the results of multiplexed subtractive proteomics verify an unparalleled selectivity of TCSG-based molecular dissection. Evidently, TCSG enables mapping of the principal biological processes taking place in a sample under study. This type of subtractive analysis in the context of the present experimental design is evidently well-suited for putative drug target and biomarker discovery.

\section{Label-free relative quantitation captures a difference in the regulation of protein orthologs detected by TCSG in both tumor stroma and tumor parenchyma}

We next used label-free quantitation [34, 35] to investigate and determine the differences in expression levels between stromal and parenchymal orthologs identified by at least one species-specific N-glycopeptide. The analysis revealed a total of $93 \mathrm{~N}$-glycoproteins that showed a significant ( $\mathrm{p}$ value $\leq 0.05$ ) divergence in regulation between these two compartments (Supplementary Table 10). Of these, the most significantly upregulated molecule in tumor stroma was a gene product of integrin alpha-1 (ITGA1), and the most upregulated molecule in tumor parenchyma is a product of the CLU gene (i.e., clusterin). Both proteins were found to play significant roles in the biology of lung adenocarcinoma $[36,37]$. These results indicate that the application/ addition of label-free relative quantitation in the context of TCSG further expands the map of the stromal and parenchymal N-glycoproteome by capturing differences in the expression profile and phenotype of species-specific protein orthologs, which are detected in both tumor compartments with no requirement for laser-based tissue microdissection prior to LC-MS analysis.

\section{Bioinformatic characterization of the stromal and parenchymal proteome corroborates the fidelity/utility of TCSG-based molecular dissection}

Next, we used the PANTHER classification system to characterize the stromal and parenchymal protein profiles. The protein class analysis of the stromal complement revealed an enrichment of structural and extracellular matrix proteins as well as transporters and defense/immunity proteins, while cell adhesion molecules, transferases, and hydrolases were enriched in the tumor parenchyma 
Table 1: Top 10 most abundant mouse-derived proteins detected solely in tumor stroma

\begin{tabular}{|c|c|c|c|c|c|}
\hline $\begin{array}{l}\text { Mouse } \\
\text { UniProt Acc \# }\end{array}$ & Gene & Protein Description & PSMs & Biological process & Reference \\
\hline Q99P91 & Gpnmb & $\begin{array}{c}\text { Transmembrane glycoprotein } \\
\text { NMB (DC-HIL) }\end{array}$ & 344 & $\begin{array}{l}\text { Negative regulation of } \\
\text { immune response }\end{array}$ & $\begin{array}{l}\text { Blood. 2007 May } \\
\text { 15;109(10):4320-7. }\end{array}$ \\
\hline P08101 & Fcgr2 & $\begin{array}{l}\text { Low affinity immunoglobulin } \\
\text { gamma Fc region receptor II }\end{array}$ & 151 & $\begin{array}{l}\text { Negative regulation of } \\
\text { immune response }\end{array}$ & $\begin{array}{l}\text { Immunity. } 2017 \mathrm{Apr} \\
\text { 18;46(4):577-586. }\end{array}$ \\
\hline Q9D7Z6 & Clca1 & $\begin{array}{l}\text { Calcium-activated chloride } \\
\text { channel regulator } 1\end{array}$ & 132 & $\begin{array}{l}\text { Inflammatory - immune } \\
\text { response }\end{array}$ & $\begin{array}{l}\text { PLoS One. } 2013 \text { Dec } \\
\text { 12;8(12):e83130 }\end{array}$ \\
\hline Q9DBP0 & Slc34a2 & $\begin{array}{l}\text { Sodium-dependent phosphate } \\
\text { transport protein } 2 \mathrm{~B}\end{array}$ & 124 & $\begin{array}{l}\text { Ab-drug conjugate } \\
\text {-cancer immunotherapy }\end{array}$ & $\begin{array}{c}\text { Clin Cancer Res. } 2015 \text { Nov } \\
\text { 15;21(22):5139-50. }\end{array}$ \\
\hline P01896 & $\mathrm{N} / \mathrm{A}$ & $\begin{array}{l}\text { H-2 class I histocompatibility } \\
\text { antigen, alpha chain }\end{array}$ & 120 & $\begin{array}{l}\text { Negative regulation of } \\
\text { immune response }\end{array}$ & $\begin{array}{l}\text { Bull Acad Natl Med. } 2014 \\
\text { Apr-May;198(4-5):801-11. }\end{array}$ \\
\hline P70232 & Chl1 & $\begin{array}{l}\text { Neural cell adhesion molecule } \\
\text { L1-like protein }\end{array}$ & 67 & $\begin{array}{c}\text { Promotes } \\
\text { tumorigenicity and } \\
\text { metastasis }\end{array}$ & $\begin{array}{c}\text { Clin Cancer Res. } 2012 \text { Apr } \\
\text { 1;18(7):1914-24. }\end{array}$ \\
\hline Q6R5N8 & Tlr13 & Toll-like receptor 13 & 65 & Innate immune response & $\begin{array}{l}\text { J Immunol. } 2012 \text { Sep } \\
\text { 15;189(6):2717-21. }\end{array}$ \\
\hline Q62192 & $\mathrm{Cd} 180$ & CD180 antigen & 59 & Immune response & $\begin{array}{l}\text { J Exp Med. 2000 Jul } \\
\text { 3;192(1):23-9. }\end{array}$ \\
\hline Q9WUL5 & Pdcd1lg2 & $\begin{array}{l}\text { Programmed cell death } 1 \\
\text { ligand } 2(\mathrm{PD}-\mathrm{L} 2)\end{array}$ & 36 & $\begin{array}{l}\text { Negative regulation of } \\
\text { immune response }\end{array}$ & $\begin{array}{l}\text { J Immunol. 2007 May } \\
\text { 1;178(9):5552-62. }\end{array}$ \\
\hline Q99NH8 & Trem2 & $\begin{array}{l}\text { Triggering receptor expressed } \\
\text { on myeloid cells } 2\end{array}$ & 34 & Immune response & $\begin{array}{l}\text { Oncotarget. } 2016 \text { May } \\
\text { 17;7(20):29620-34. }\end{array}$ \\
\hline
\end{tabular}

(Supplementary Figure 3). PANTHER pathway analysis revealed the amplification of VGEF signaling, endothelin signaling angiogenesis, chemokine/cytokine inflammation signaling, and $\mathrm{T}$ - and B-cell activation in the tumor stroma. The same analysis revealed cadherin signaling; EGF receptor signaling; and Wnt, Notch, and Hedgehog signaling activation in the tumor parenchyma (Supplementary Figure 4). The results of the bioinformatic molecular classification are concordant with the well-recognized roles of the tumor stroma in cancer biology (e.g., angiogenesis, immune response) as well as the roles of the parenchyma (i.e., malignant tumor cells) in tumorigenesis, as exemplified by the amplification of proliferative signals (e.g., EGF and Wnt signaling). These findings further corroborate the fidelity/ utility of TCSG-based molecular dissection that enables advanced characterization and phenotyping of the tumor proper and its microenvironment.

\section{Pathway analysis revealed cellular movement, tumor proliferation, tumor invasion, and metastasis as the top functional networks in the tumor parenchyma}

To assess the biological relevance of results obtained by virtual dissection of tumor parenchyma from the stroma and to prioritize cross-validation targets, a subset of proteins unique to and/or found upregulated in tumor parenchyma were analyzed using the Ingenuity Pathway Analysis (IPA ${ }^{\circledR}$ ) [QIAGEN Redwood City, www.qiagen.com/ingenuity]. The IPA $^{\circledR}$ revealed cell migration, tumor invasion, advanced malignancy, and tumor metastasis as the top parenchymal functional networks (Supplementary Table 11A) based on statistical significance and the number of interacting protein species detected. To cross-validate the results of the IPA ${ }^{\circledR}$, we set out to confirm the identification and topology of CD147, CD44, and CDH17 depicted in tumor invasion and tumor metastasis networks (Supplementary Figures 5-6).

We first selected basigin (CD147), a product of the BSG gene depicted in the tumor invasion network (Supplementary Figure 5). Other groups, including ours, have previously shown that CD147 plays an important role in the biology of KRAS-driven cancers [38-40]. Selected $\mathrm{MS}^{2}$ spectra depicting the identification of human-derived parenchymal CD147 via protein- and species-specific $\mathrm{N}$-glycopeptides are shown in Supplementary Figures 7-8. Next, BLAST analysis compared the sequences of the human CD147 and corresponding mouse ortholog and confirmed the topology and protein/species specificity of the identified N-glycopeptides, which is underlined in red in Supplementary Figure 9. 
Table 2: Top 10 most abundant human-derived proteins detected solely in tumor parenchyma

\begin{tabular}{|c|c|c|c|c|c|}
\hline $\begin{array}{l}\text { Human } \\
\text { UniProt Acc \# }\end{array}$ & Gene & Protein Description & PSMs & $\begin{array}{l}\text { Biological } \\
\text { process }\end{array}$ & Reference \\
\hline P06731 & CEACAM5 & $\begin{array}{l}\text { Carcinoembryonic antigen-related } \\
\text { cell adhesion molecule } 5\end{array}$ & 1003 & Metastasis & $\begin{array}{c}\text { Cancer Metastasis Rev. } 2013 \\
\text { Dec;32(3-4):643-71. }\end{array}$ \\
\hline Q9HC84 & MUC5B & Mucin-5B & 215 & Metastasis & $\begin{array}{l}\text { Int J Cancer. } 1996 \text { Dec } \\
\text { 20;69(6):457-65. }\end{array}$ \\
\hline Q9Y6R7 & FCGBP & IgGFc-binding protein & 211 & Metastasis & $\begin{array}{l}\text { Oncol Lett. } 2016 \\
\text { Jan;11(1):568-574. }\end{array}$ \\
\hline Q7Z7M9 & GALNT5 & $\begin{array}{c}\text { Polypeptide N-acetylgalactosaminyl } \\
\text { transferase } 5\end{array}$ & 150 & Metastasis & $\begin{array}{l}\text { Oncotarget. } 2016 \text { Aug } \\
16 ; 7(33): 54067-54081 .\end{array}$ \\
\hline Q9HD43 & PTPRH & $\begin{array}{c}\text { Receptor-type tyrosine-protein } \\
\text { phosphatase } \mathrm{H}\end{array}$ & 117 & Tumor growth & $\begin{array}{l}\text { Nat Rev Cancer. } 2011 \\
\text { Jan;11(1):35-49. }\end{array}$ \\
\hline O75015 & FCGR3B & $\begin{array}{l}\text { Low affinity immunoglobulin } \\
\text { gamma Fc region receptor III-B }\end{array}$ & 105 & Metastasis & $\begin{array}{l}\text { Eur J Cancer. } 2010 \\
\text { Jul;46(10):1829-34. }\end{array}$ \\
\hline P98088 & MUC5AC & Mucin-5AC (Fragments) & 99 & $\begin{array}{l}\text { Enhances } \\
\text { metastasis }\end{array}$ & $\begin{array}{l}\text { Oncogene. } 2016 \text { Aug } \\
4 ; 35(31): 4112-21\end{array}$ \\
\hline Q12864 & CDH17 & Cadherin-17 (CDH17) & 66 & $\begin{array}{l}\text { Enhances } \\
\text { metastasis }\end{array}$ & $\begin{array}{l}\text { Oncogene. } 2014 \text { Mar } \\
\text { 27;33(13):1658-69 }\end{array}$ \\
\hline P01009 & SERPINA1 & Alpha-1-antitrypsin & 54 & $\begin{array}{l}\text { Invasion and } \\
\text { migration }\end{array}$ & $\begin{array}{l}\text { Oncotarget. 2015 Aug } \\
\text { 21;6(24):20312-26. }\end{array}$ \\
\hline Q9UKN1 & MUC12 & Mucin-12 & 46 & $\begin{array}{l}\text { Tumor cell } \\
\text { growth regulation }\end{array}$ & $\begin{array}{l}\text { Cancer Res. } 1999 \text { Aug } \\
\text { 15;59(16):4083-9. }\end{array}$ \\
\hline
\end{tabular}

We applied IHC to analyze the tumor xenograft using a human CD147-specific antibody. The tumor xenograft IHC showed membrane staining exclusively on parenchymal cells (Figure 3A) as well as its absence in normal mouse lung tissue (Figure 3C). The human origin of parenchymal cells is confirmed by an IHC using a human MHC-I-specific antibody (Figure 3B). The expression and membrane subcellular localization of CD147 was further validated by immunofluorescence (IF) in 2D-grown A549 cells (Figure 4A-4C). The IF confirmed the expression of the human CD147 at the surface of A549 cells, and it is consistent with our previous findings showing that CD147 localizes at the surface of cancer cell lines expressing oncogenic KRas mutants endogenously [38]. Additionally, we carried out a western blot (WB) analysis of tumor tissue homogenate using a human-specific CD147 antibody that verified CD147 expression in tumor xenograft homogenate and human heart homogenate (i.e., positive control). Correspondingly, WB analysis using the same antibody was negative in normal mouse lungs and mouse heart (i.e., negative control), as shown in Supplementary Figure 10. These findings are concordant with the TCSG results and support our hypothesis.

Mouse-derived CD147 ortholog was identified in normal/healthy mouse lungs (Supplementary Table
7A) and is shown underlined in blue (Supplementary Figure 9). Human-derived CD147 (Supplementary Table 7B) was detected in 2D-grown A549 human lung adenocarcinoma cells via protein- and species-specific peptides and is shown underlined in green (Supplementary Figure 9). Depicted in Supplementary Figures 12-13 are the selected $\mathrm{MS}^{2}$ spectra of protein- and species-specific $\mathrm{N}$-glycosylated peptides identifying mouse-derived CD147 in normal lungs (Supplementary Figure 11) and the human-derived CD147 ortholog in 2D-grown A549 cells. Next, we cross-validated the identification of the mousederived CD147 in normal/healthy lungs using a mousespecific CD147 antibody. The immunostaining confirmed the expression of the mouse-derived CD147 ortholog in normal lungs, directly validating the TCSG results, and is shown in Figure 4D. In summary, these results designate CD147 as a prototypical proof-of-principle molecule that depicts unparalleled selectivity of TCSG for molecular profiling of human-mouse xenografts.

Next, we set out to investigate in silico if this glycopeptide-based selectivity is conserved across primate species exhibiting high similarity with the human proteome (e.g., chimpanzees). We used CD147 as a model molecule and carried out BLAST analysis to compare sequences of the human CD147 with chimpanzee and gorilla orthologs. The analysis (Supplementary Figures 
Table 3: Top 10 most abundant human-derived proteins detected solely in 2D-grown A549 cells

\begin{tabular}{|c|c|c|c|c|c|}
\hline $\begin{array}{l}\text { Human } \\
\text { UniProt Acc \# }\end{array}$ & Gene & Protein Description & PSMs & Biological process & Reference \\
\hline Q16288 & NTRK3 & NT-3 growth factor receptor & 258 & $\begin{array}{l}\text { Increases cell } \\
\text { proliferation }\end{array}$ & $\begin{array}{l}\text { Oncogene. } 2013 \text { Aug } \\
8 ; 32(32): 3698-710\end{array}$ \\
\hline Q92823 & NRCAM & $\begin{array}{l}\text { Neuronal cell adhesion } \\
\text { molecule }\end{array}$ & 197 & $\begin{array}{l}\text { Increases cell } \\
\text { proliferation }\end{array}$ & $\begin{array}{c}\text { Genes Dev. } 2002 \text { Aug } \\
\text { 15;16(16):2058-72 }\end{array}$ \\
\hline Q13433 & SLC39A6 & Zinc transporter ZIP6 & 133 & $\begin{array}{l}\text { Increases cell } \\
\text { proliferation }\end{array}$ & PLoS One. 2013;8(2):e56542. \\
\hline P10586 & PTPRF & $\begin{array}{l}\text { Receptor-type tyrosine- } \\
\text { protein phosphatase } \mathrm{F}\end{array}$ & 120 & $\begin{array}{l}\text { Increases cell } \\
\text { proliferation }\end{array}$ & $\begin{array}{l}\text { J Biol Chem. } 2006 \text { Jun } \\
\text { 16;281(24):16482-92. }\end{array}$ \\
\hline O75503 & CTSC & Dipeptidyl peptidase 1 & 96 & $\begin{array}{l}\text { Growth of cultured } \\
\text { cells }\end{array}$ & $\begin{array}{c}\text { Proc Natl Acad Sci U S A. } 2004 \\
\text { Nov 2;101(44):15724-9. }\end{array}$ \\
\hline P53634 & ASAH1 & Acid ceramidase & 89 & $\begin{array}{l}\text { Increases cell } \\
\text { proliferation }\end{array}$ & $\begin{array}{l}\text { J Biol Chem. 2011 Jun } \\
\text { 3;286(22):19399-409. }\end{array}$ \\
\hline Q13510 & CELSR1 & $\begin{array}{l}\text { Cadherin EGF LAG seven- } \\
\text { pass G-type receptor } 1\end{array}$ & 79 & Migration & $\begin{array}{l}\text { J Neurosci. } 2010 \text { Jul } \\
\text { 14;30(28):9392-401. }\end{array}$ \\
\hline P29317 & EPHA2 & Ephrin type-A receptor 2 & 65 & $\begin{array}{l}\text { Increases cell } \\
\text { proliferation }\end{array}$ & $\begin{array}{l}\text { Oncogene. } 2011 \text { Dec } \\
\text { 15;30(50):4921-9. }\end{array}$ \\
\hline P13987 & CD59 & CD59 glycoprotein OS & 64 & $\begin{array}{l}\text { Increases cell } \\
\text { proliferation }\end{array}$ & $\begin{array}{l}\text { Cell Immunol. } 2011 ; 272(1): 61- \\
70 .\end{array}$ \\
\hline O60911 & CTSV & Cathepsin L2 OS & 53 & $\begin{array}{l}\text { Increases cell } \\
\text { proliferation }\end{array}$ & $\begin{array}{l}\text { Nat Commun. } 2014 \text { Sep } \\
\text { 15;5:4931. }\end{array}$ \\
\hline
\end{tabular}

14-15) showed that the human CD147 is $96.3 \%$ and $96.6 \%$ identical to chimpanzee and gorilla orthologs. Even at this high sequence similarity rate, all in silico predicated MSidentifiable N-glycopeptides from each of the three CD147 orthologs (i.e., human, gorilla, and chimp) were found to be species-specific identifiers. These findings suggest that the dissimilarity rate of the CD147 N-glycosylated peptides is highly conserved even across phylogenetically close species (i.e., primates) and further corroborates our hypothesis.

The CD44 antigen (CD44), depicted in the tumor invasion network (Supplementary Figure 5) was selected for orthogonal cross-validation because of its well-described role in tumorigenesis and invasion of lung adenocarcinoma driven by oncogenic KRas mutants [41, 42]. Selected $\mathrm{MS}^{2}$ spectra depicting the identification of human-derived parenchymal CD44 via protein- and species-specific N-glycopeptides are shown in Supplementary Figures 16-17. The BLAST analysis comparing the sequences of human CD44 and its mouse ortholog, which confirmed the topology as well as the protein and species specificity of human-derived $\mathrm{N}$-glycopeptides, is underlined in red (Supplementary Figure 18). The IHC analysis unambiguously confirmed the parenchymal location of CD44 (Figure 5A). CD44 was also identified in a 2D-grown A549 cell control
(Supplementary Table 5B). Notably, using A549-derived CD44 ${ }^{+}$cancer stem cells, Guo et al. observed an increased expression of PKM2 and proposed it as a putative drug target for lung adenocarcinoma [43]. It has also been shown that CD44 forms complexes with CD147 at the cell surface of cancer cell lines [39,44], which is indicative of the pivotal and complex role CD147 plays in KRas-driven tumors.

Cadherin-17, depicted in the tumor metastasis network (Supplementary Figure 6), was identified by TCSG exclusively in the tumor parenchyma, with no detection in 2D-grown A549 cells or normal lung tissue. While the role of CDH17 in the biology of gastrointestinal malignancies is well documented, [45] its role in lung cancer biology has not been well established. Selected $\mathrm{MS}^{2}$ spectra depicting the identification of the parenchymal human-derived cadherin-17 via proteinand species-specific N-glycopeptides are shown in Supplementary Figures 19-20. The BLAST analysis comparing the sequences of human CDH17 and its mouse ortholog, which confirmed the topology as well as the protein and species specificity of the identified human-derived $\mathrm{N}$-glycopeptides, is underlined in red (Supplementary Figure 21). Subsequent IHC analysis validated the localization of the human CDH17 in the tumor xenograft parenchyma (Figure 5B). Overall, the 
Table 4: Top 10 most abundant mouse-derived proteins detected solely in normal mouse lungs

\begin{tabular}{|c|c|c|c|c|c|}
\hline $\begin{array}{l}\text { Mouse } \\
\text { UniProt A }\end{array}$ & Gene & Protein Description & PSMs & Biological process & Reference \\
\hline Q8K442 & Abca8a & $\begin{array}{l}\text { ATP-binding cassette sub-family } \\
\text { A member 8-A }\end{array}$ & 155 & Lipid transport & $\begin{array}{c}\text { Mamm Genome. } 2003 \\
\text { Jan;14(1):7-20 }\end{array}$ \\
\hline P48356 & Lepr & Leptin receptor & 47 & $\begin{array}{l}\text { Regulation of lipid } \\
\text { metabolism }\end{array}$ & $\begin{array}{l}\text { Hepatology. } 2014 \\
\text { Jul;60(1):133-45. }\end{array}$ \\
\hline Q8BWP8 & B4gat1 & Beta-1,4-glucuronyltransferase 1 & 46 & Protein glycosylation & $\begin{array}{c}\text { Elife. } 2014 \text { Oct } 3 ; 3 \text {. doi: } \\
\text { 10.7554/eLife. } 03941 .\end{array}$ \\
\hline P08508 & Fcgr3 & $\begin{array}{l}\text { Low affinity immunoglobulin } \\
\text { gamma Fc region receptor III }\end{array}$ & 45 & $\begin{array}{l}\text { Immune response } \\
\text { regulation }\end{array}$ & $\begin{array}{l}\text { J Immunol. 1998 Sep } \\
\text { 15;161(6):3026-32. }\end{array}$ \\
\hline O35632 & Hyal2 & Hyaluronidase- 2 & 43 & Hyaluronic acid binding & $\begin{array}{l}\text { Histochem Cell Biol. } \\
\text { 2016 Jan;145(1):53-66 }\end{array}$ \\
\hline Q8C6K9 & Col6a6 & Collagen alpha-6(VI) chain & 41 & Cell adhesion & $\begin{array}{l}\text { J Biol Chem. } 2008 \text { Jul } \\
\text { 18;283(29):20170-80. }\end{array}$ \\
\hline Q80WV3 & Chst2 & Carbohydrate sulfotransferase 2 & 39 & Inflammatory response & $\begin{array}{l}\text { J Leukoc Biol. } 2001 \\
\text { Apr;69(4):565-74. }\end{array}$ \\
\hline P06339 & $\mathrm{H} 2-\mathrm{T} 23$ & $\begin{array}{l}\text { H-2 class I histocompatibility } \\
\text { antigen, D-37 alpha chain }\end{array}$ & 39 & $\begin{array}{l}\text { Adaptive immune } \\
\text { response }\end{array}$ & $\begin{array}{l}\text { J Immunol. } 2014 \text { Aug } \\
\text { 1;193(3):1427-39. }\end{array}$ \\
\hline Q6NVD0 & Frem2 & $\begin{array}{l}\text { FRAS1-related extracellular } \\
\text { matrix protein } 2\end{array}$ & 38 & Cell adhesion & $\begin{array}{l}\text { Histochem Cell Biol. } \\
2008 \text { Oct;130(4):785-93. }\end{array}$ \\
\hline P01897 & $\mathrm{H} 2-\mathrm{L}$ & $\begin{array}{l}\text { H-2 class I histocompatibility } \\
\text { antigen, L-D alpha chain }\end{array}$ & 37 & Immune systems process & $\begin{array}{l}\text { Cell. 1986 Jan } \\
\text { 31;44(2):261-72. }\end{array}$ \\
\hline
\end{tabular}

bioinformatic characterization of the molecular profiles, the pathway analyses, and the subsequent cross-validation of the selected targets all highlight the potential of TCSG technology to improve our understanding of cancer biology and facilitate the discovery of putative parenchymal biomarkers and druggable targets.

\section{Pathway analysis revealed leukocyte immune response, humoral immune response, cellular immune response, and movement disorder as the top functional networks in the tumor stroma}

Focusing on the stromal molecular phenotype obtained by TCSG, we applied the network analysis feature of IPA ${ }^{\circledR}$ on a subset of N-glycoproteins identified uniquely and/or found upregulated in the tumor stroma. The analysis revealed leukocyte immune response, humoral immune response, cellular immune response, and movement disorder as the top stromal functional networks (Supplementary Table 11B) based on statistical significance and the number of interacting N-glycoproteins identified. The outcome of the IPA ${ }^{\circledR}$ is concordant with the role of the tumor stroma (i.e., tumor microenvironment) in tumor biology [46], revealing the activation of different immune response modalities that are critical for tumor immune evasion and survival. From the top protein networks, we selected the programmed cell death 1 ligand 2 (PD-L2), Pdcd1lg2 gene product, and the oxidized lowdensity lipoprotein receptor 1 (LOX-1) - a product of the Olr1 gene-for IHC-based cross-validation.

PD-L2 is depicted in the leukocyte immune response network (Supplementary Figure 22). The $\mathrm{MS}^{2}$ spectrum depicting the identification of the mouse PDL2 ortholog in a species- and protein-specific manner is shown in Supplementary Figure 23. The BLAST analysis (Supplementary Figure 24) depicts the protein- and species-specific N-glycopeptide identifying the mouse PD-L2. The IHC staining reveals the stromal expression of PD-L2 (Figure 5C) and is found predominantly on the surface of immune cell infiltrates. While PD-L1 is still the only predictive biomarker for PD-L1/PD1 immunotherapy (i.e., nivolumab, pembrolizumab) for metastatic lung adenocarcinoma, our findings are in agreement with an increasing number of publications suggesting that additional companion IHC diagnostics targeting stromal PD-L2 may offer better prediction for targeted immunotherapy [47, 48]. Thus, PD-L2 may serve as an additional companion diagnostic marker and putative stromal target for metastatic adenocarcinoma of the lung.

LOX-1, a product of the Olr1 gene, is shown in the leukocyte migration network (Supplementary Figure 25). The representative $\mathrm{MS}^{2}$ spectrum of a glycopeptide 
identifying the mouse LOX-1 ortholog is shown in Supplementary Figure 26. The BLAST analysis confirms the protein and species specificity of the same peptide and is shown in Supplementary Figure 27. The IHC analysis confirmed explicitly the stromal LOX-1 location (Figure 5C) within the immune cell infiltrates. Unlike PD-L2, the role of LOX-1 in the biology of adenocarcinoma of the lung is poorly understood. Nonetheless, our findings are
A

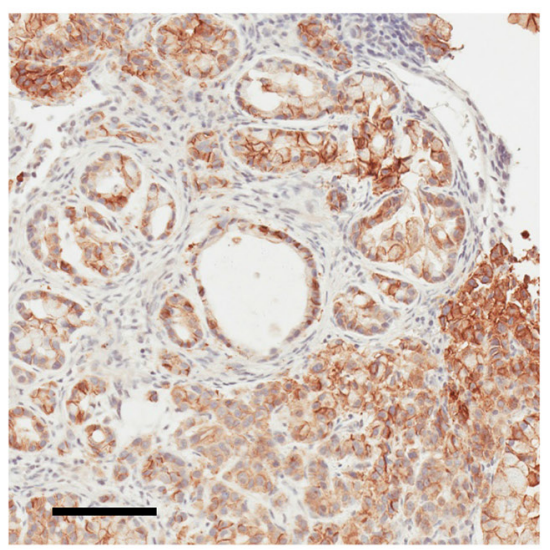

B

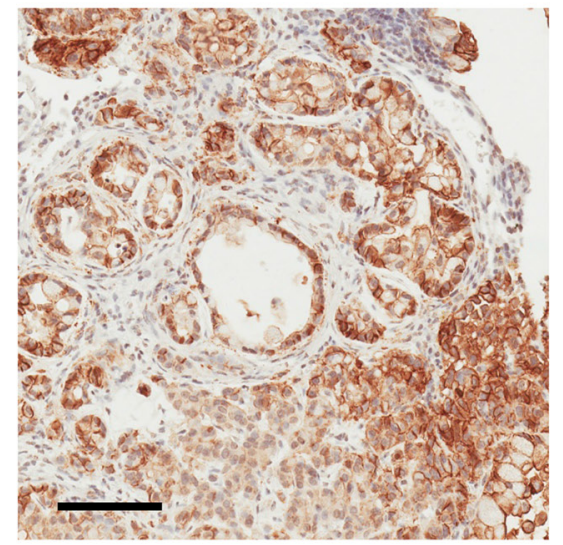

C

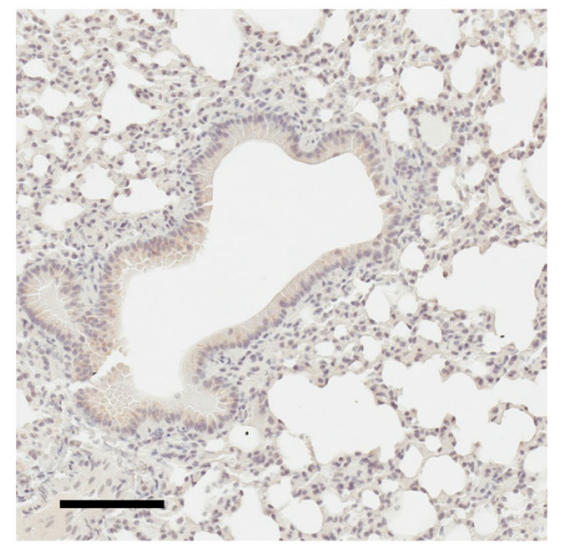

Figure 3: IHC-based validation of human-derived CD147 expression in tumor parenchyma. (A) IHC staining for humanderived CD147 in tumor xenograft obtained employing the human-specific CD147 antibody. (B) IHC staining for human MHC I obtained employing anti-human MHC I antibody. (C) Absence of IHC staining in normal mouse lungs employing human-specific CD147 antibody. $\operatorname{Bar}=100 \mu \mathrm{m}$.
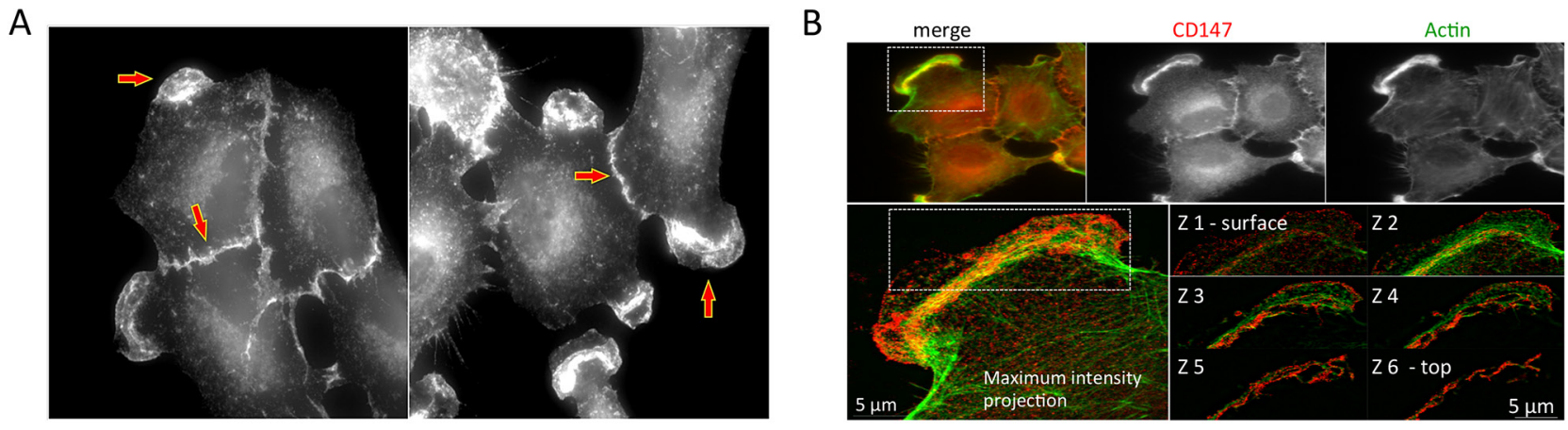

C

D
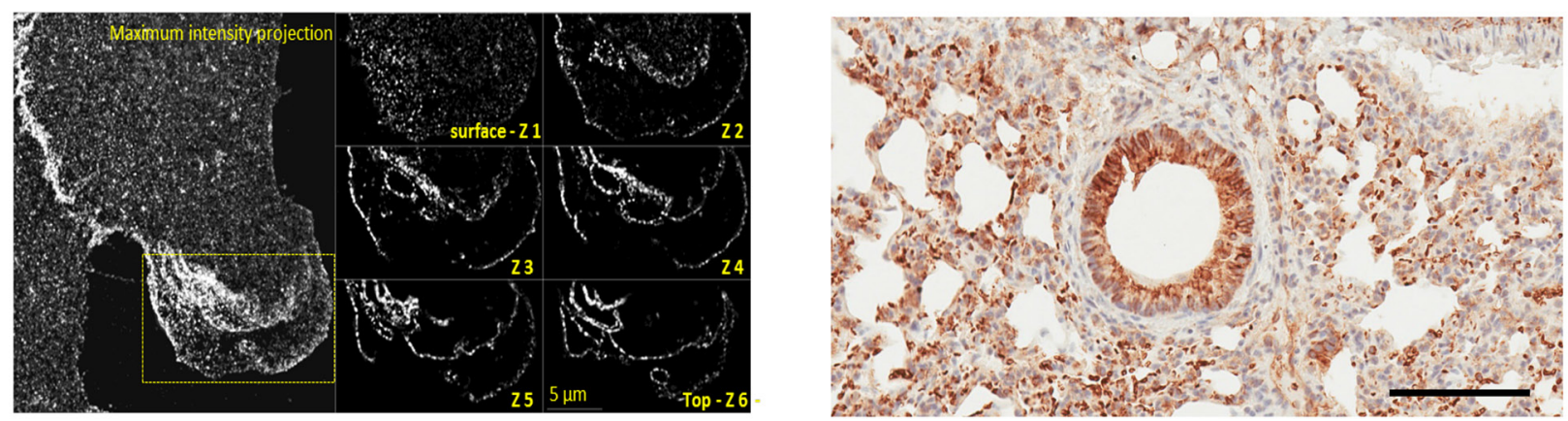

Figure 4: Cross-validation of the CD147 expression in human 2D-grown A549 cells and its mouse ortholog in the parenchyma of normal mouse lungs. (A) A549 cells: wide-field fluorescence microscopy analysis of immunolabeled CD147 using anti-mouse specific antibody. (B) A549 cells: SIM analysis of the cell from (A) detailing localization of CD147 on cell membrane. (C) A549 cells: wide-field fluorescence showing colocalization of CD147 and Actin. (D) Normal mouse lungs: IHC staining for parenchymal mouse-derived CD147 using the mouse-specific CD147 antibody. Bar $=100 \mu \mathrm{m}$. 
consistent with results obtained by transcriptomic analysis showing amplified LOX-1 expression in tumor-associated neutrophils in mice [49], as well as with findings showing a LOX-1-dependent enhancement of angiogenesis in prostate cancer tumor xenografts confirmed by biological assay [50].

In summary, the cross-validation verified the utility of TCSG for molecular differentiation/dissection of these two functionally and morphologically codependent complex tumor compartments. To the best of our knowledge, this the first study that investigated and compared the differences between human and mouse MS-identifiable N-glycopeptidomes. A TCSG approach was developed that enabled the dissection of tumor stroma from tumor parenchyma in human-murine tumor xenografts at the molecular level, along with a selectivity and specificity rate currently unattainable by other means.

\section{The translational relevance of the data obtained by TCSG}

The translational relevance and the utility of the results obtained by the TCSG platform were evaluated by carrying out a proof-of-principle experiment focused on cross-validation of selected targets in matching human clinical tissue specimens. Several parenchymal and stromal targets detected by TCSG in the tumor xenograft were selected for IHC-based validation on human lung adenocarcinoma tissue known to contain an oncogenic KRas mutant. To mitigate the impact of natural molecular heterogeneity present at the proteome level in the human population proper, the tumor tissue and normal adjacent tissue were collected from the same patient. From the top parenchymal networks (Supplementary Table 11A), we selected two targets, CD147 and CDH17, that were found in malignant tumor

B

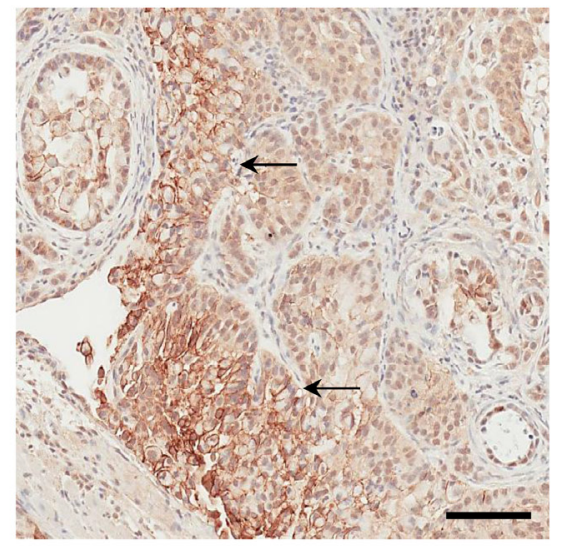

D

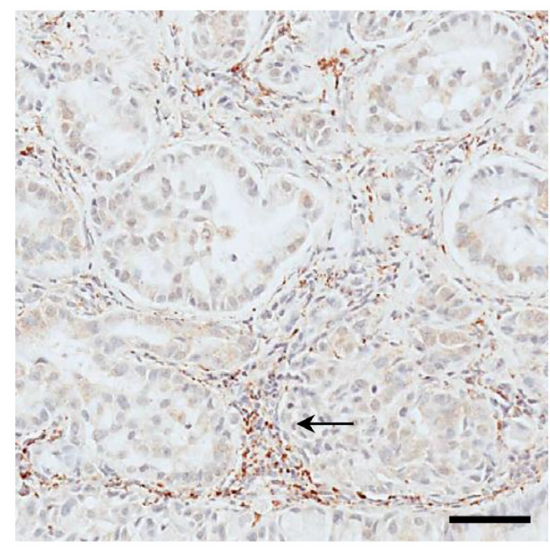

Figure 5: Cross-validation of parenchymal CD44 and CDH17 expression and stromal PD-L2 and ORL-1 expression in tumor xenograft tissue. (A) Parenchymal CD44 immunostaining. (B) Parenchymal CDH17 immunostaining. (C) Stromal PD-L2 immunostaining. (D) Stromal LOX-1 immunostaining. Bar $=100 \mu \mathrm{m}$. 
invasion (Supplementary Figure 5) and tumor metastasis networks (Supplementary Figure 6), respectively. From the top stromal networks (Supplementary Table 11B), we also selected transmembrane glycoprotein NMB (DC-HIL), Gpnmb gene product, and ectonucleotide pyrophosphatase/phosphodiesterase family member 5 (NPP-5), Enpp5 gene product, that were found in stromal humoral immune response (Supplementary Figure 28) and movement disorder networks (Supplementary Figure 32), respectively.

IHC staining of CD147 confirmed the parenchymal location in the human adenocarcinoma lung tissue. A much higher expression level of CD147 in tumor tissue compared to normal adjacent tissue (Figure 6A-6B) was observed. The role of CD147 in invasion and metastasis of human lung cancer is well described [51]. Previously, we have shown that the expression pattern of CD147 in the context of the oncogenic KRas-driven malignant transformation is highly conserved. Essentially, we showed that CD147 exhibits an identical surface expression pattern in a model of a KRastransfected/transformed cell line (MCF10A-KRas ${ }^{\mathrm{G} 12 \mathrm{~V}}$ ) as well as in pancreatic (KP3), lung (H2444), and colon (SW620) cancer cell lines expressing KRas mutants endogenously [38]. This study showed that the CD147 protein signature displays the same location at the surface of 2D-grown A549 cells in the parenchyma of a murine lung adenocarcinoma xenograft and in human lung adenocarcinoma. This is depicted in Figures 3, 4, and 6 and indicates a high translational relevance of the TCSG platform.

An intense parenchymal CDH17 staining was observed in human lung adenocarcinoma tissue (Figure $6 \mathrm{C})$, and CDH17 was absent in the normal adjacent tissue (Figure 6D), which agrees with the corresponding LC-MS data obtained using TCSG (Supplementary Figures 1920). While the role of CDH17 in lung adenocarcinoma is not well understood, our IHC findings are consistent with results obtained via tissue microarrays targeting CDH17 in patients diagnosed with metastatic colorectal adenocarcinoma [52]. Hence, CDH17 depicted in the tumor metastasis network (Supplementary Figure 6) may be added to a cytokeratin panel [53] for better classification of the metastatic human lung adenocarcinoma.

DC-HIL depicted in the humoral response network (Supplementary Figure 28) is a well-described immunomodulatory molecule that plays a critical role in tumor progression and metastasis in multiple solid malignancies, including lung cancer [54]. Selected $\mathrm{MS}^{2}$ spectra depict the identification of the mouse DC-HIL in a species- and protein-specific manner (Supplementary Figures 29-30). The BLAST analysis (Supplementary Figure 31) verifies the protein and species specificity of the identified DC-HIL N-glycopeptides. Figure 7A shows positive stromal DC-HIL immunostaining in human lung adenocarcinoma tissue and weak or negative staining in normal adjacent lung tissue (Figure 7B). These findings are in direct agreement with LC-MS results obtained by
TCSG. DC-HIL was detected as the most abundant protein unique to the tumor stroma (Table 1A). Like PD-1, DCHIL functions as a negative regulator of T-cell activation [55]. An antibody-drug conjugate that targets DC-HIL is now in clinical trials [54].

NPP-5, depicted in the movement disorder network (Supplementary Figure 33), stimulates cell motility [56] and plays a significant role in pediatric high-grade glioma neo-angiogenesis [57]. In comparison with normal adjacent lung tissue, the stroma of human lung adenocarcinoma shows strong positive overexpression of NPP-5 in the IHC analysis (Figure 7C) and weak or negative expression in the stroma of non-tumorous adjacent lung tissue (Figure 7D). These findings are consistent with LC-MS results obtained by TCSG. The $\mathrm{MS}^{2}$ spectrum depicts the identification of the mouse NPP-5 in a species- and protein-specific manner (Supplementary Figure 34). The BLAST analysis verifies the protein and species specificity of the identified NPP5 N-glycopeptides (Supplementary Figure 34). Unlike DC-HIL, the role of NPP-5 in the biology of lung cancer is poorly understood, and the present results make NPP5 a putative target (at best) for lung adenocarcinoma therapy. These results strongly support the translational potential of TCSG and its ability to facilitate a better understanding of tumor biology as well as the discovery of putative therapeutic candidates that would enable concomitant targeting of these two codependent solid tumor compartments.

\section{DISCUSSION}

While immune detection remains a mainstay technology (e.g., IHC, mass cytometry) in the molecular profiling of malignant tumors, its depth and scope are limited by the shortage of reliable antibodies applicable to "in-advance" selected targets. Discovery is limited. Conversely, antibody-free proteomics that relies on laserbased microdissection to separate tumor stroma from tumor parenchyma prior to LC-MS analysis is hindered by limited sample size, uncertain specimen homogeneity, tedium, and costly operator-dependent instrumentation.

Similarly, cross-species-reliant MS-based tumor xenograft proteomics, which exploits the differences between the plain/unmodified human and mouse MSidentifiable peptidome, is constrained by the fact that $60 \%$ of human and mouse MS-identifiable peptides share the same sequence (Figure 1). This greatly limits the range and capacity to differentiate between the stromal (i.e., mouse) and parenchymal (i.e., human) protein species, rendering $\sim 50 \%$ of peptide identifications wasted. Recent advances in cancer immunotherapy targeting malignant tumor cells (i.e., parenchymal targets) using biologicals (e.g., therapeutic antibodies) [58] or cells of the tumor microenvironment (i.e., stromal targets) using small molecules (e.g., angiogenesis inhibitors) [59] underscore 
a need for improved molecular diagnostic approaches. Antibody-free proteomic technologies capable of unbiased, in-depth characterization of the tumor stroma and tumor parenchyma in xenograft model systems are an advance in this direction [60].

Described in this study is a potent antibodyfree MS-based approach for proteome-scale molecular dissection of tumor stroma from tumor parenchyma in murine xenografts at a differentiation rate currently unattainable by other means. The TCSG approach is discovery-based. It also allows for more selective and specific molecular mapping of these two functionally and anatomically codependent compartments. It relies primarily on our discovery showing for the first time the exceedingly higher dissimilarity rate (i.e., $72 \%$ ) between mouse and human MS-identifiable N-glycopeptidomes. By comparison, the plain, unmodified MS-identifiable peptidome shows a dissimilarity rate of only $40 \%$ (Figure
1). As an illustration, BLAST analysis of the human, gorilla, and chimpanzee CD147 orthologs targeting MS-identifiable N-glycosylated peptides showed their conserved species-specific attributes despite the fact that CD147 sequences possess an identity of $\geq 96.3 \%$. This is depicted in Supplementary Figures 15-16.

Coupling TCSG with IPA ${ }^{\circledR}$ elucidated the top parenchymal tumor networks (i.e., invasion, advanced malignant tumor, and metastasis). These networks contain human-derived N-glycoproteins with an already-established linkage/role in lung adenocarcinoma signaling (e.g., CD44, CD147) and proteins whose relevance to the biology of lung adenocarcinoma is less clear (e.g., CDH17). In parallel, the IPA ${ }^{\circledR}$ of the stromal $\mathrm{N}$-glycoprotein complement revealed a humoral immune response, cellular immune response, and immune response of leukocytes as top immune networks. These were activated in the mouse-derived lung adenocarcinoma
A

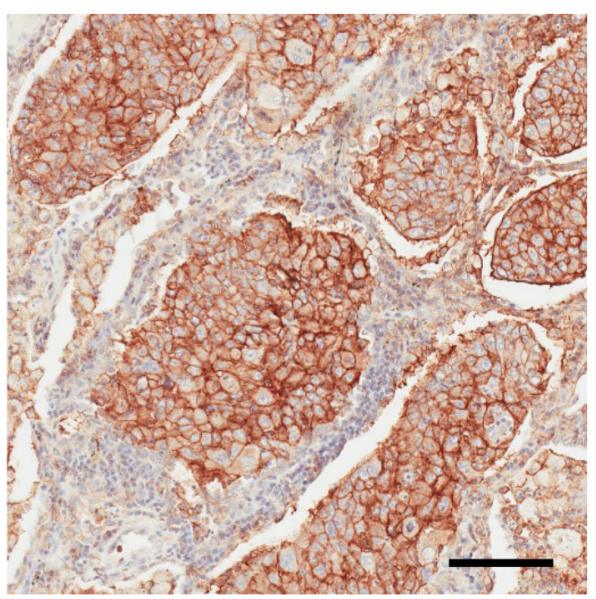

C

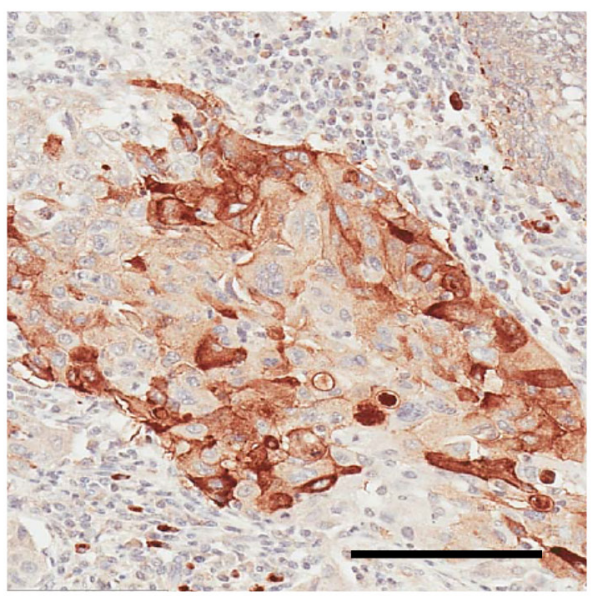

B

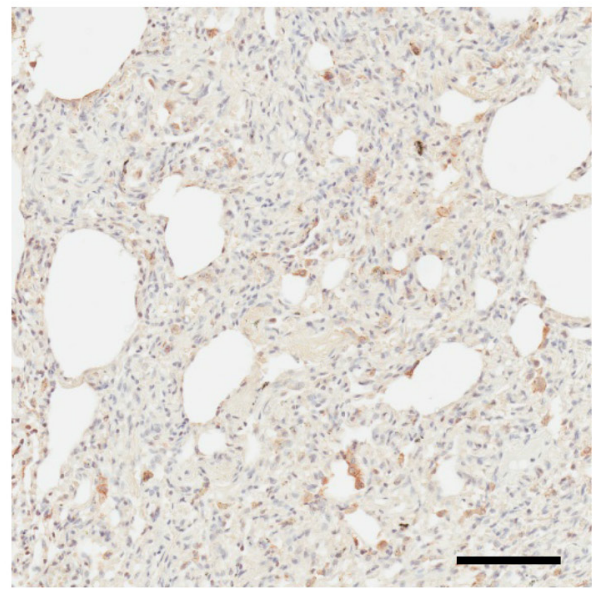

D

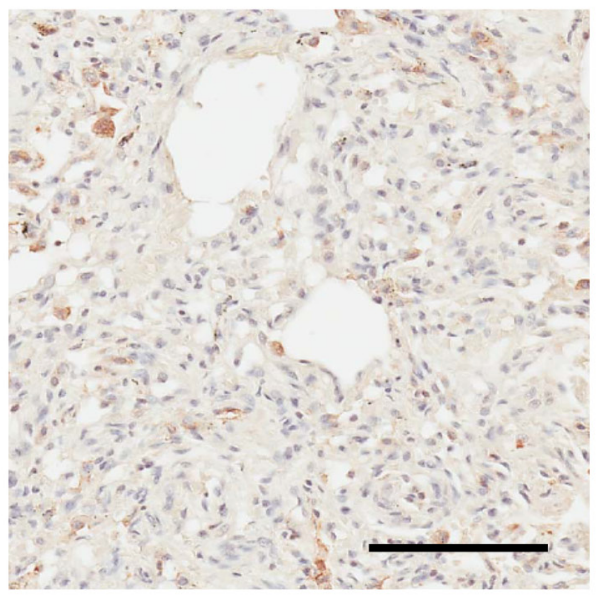

Figure 6: IHC analysis of CD147 and CDH17 in human lung adenocarcinoma and non-cancerous adjacent tissue. (A) Strong positive CD147 staining in human lung adenocarcinoma. (B) Weak or negative CD147 staining in adjacent non-tumorous lung tissue. (C) Strong positive CDH17 staining in human lung adenocarcinoma. (D) Weak or negative CDH17 staining in adjacent nontumorous lung tissue. Bar $=100 \mu \mathrm{m}$. 
microenvironment depicting protein species with known roles in tumor immune evasion (e.g., PD-L2) or others whose role in the biology of lung adenocarcinoma is currently not well understood (e.g., Gpnmb). The IHCbased cross-validation of TCSG results for selected targets verified their spatial distribution within the tumor stroma and tumor parenchyma, leading to a better understanding of lung adenocarcinoma biology.

In addition, we discovered that TCSG-based molecular mapping of the tumor stroma and tumor parenchyma in mouse xenografts is further enhanced by applying subtractive proteomic analysis to control samples (i.e., 2D-grown A549 cells, normal mouse lungs). This analysis revealed a subset of $\mathrm{N}$-glycoproteins exclusively detected in 2D-grown A549 cells that may be pivotal for a better understanding of Petri dish biology and/or proteins identified solely in healthy lungs that may facilitate a better understanding of respiratory processes. Alternatively, in the context of the present experimental design (Figure 2), the TCSG platform applied on the current mouse lung adenocarcinoma metastatic model may be used for rapid quantitative measurement of selected targets in a series of follow-up experiments to monitor changes in their relative concentration subsequent to experimental alterations (e.g., drug treatment).

This study begins to address the basic shortage of feasible stromal and parenchymal targets in metastatic lung adenocarcinoma mouse xenograft models. As a part of the NCI's RAS initiative (www.cancer.gov/research/ key-initiatives/ras), the Frederick National Laboratory for Cancer Research (FNLCR) utilizes MS-based proteomics to identify and characterize putative drug targets using cell lines [38, 61] and mouse models expressing oncogenic Ras mutants. FNLCR has pioneered MS-based methods for profiling clinical tissue specimens [29, 35, 62, 63] and mouse models expressing Ras mutants [64]. Using

\section{A}

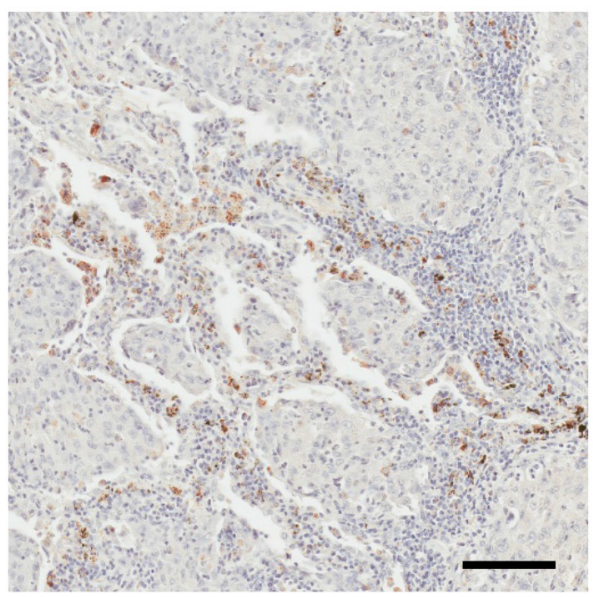

C

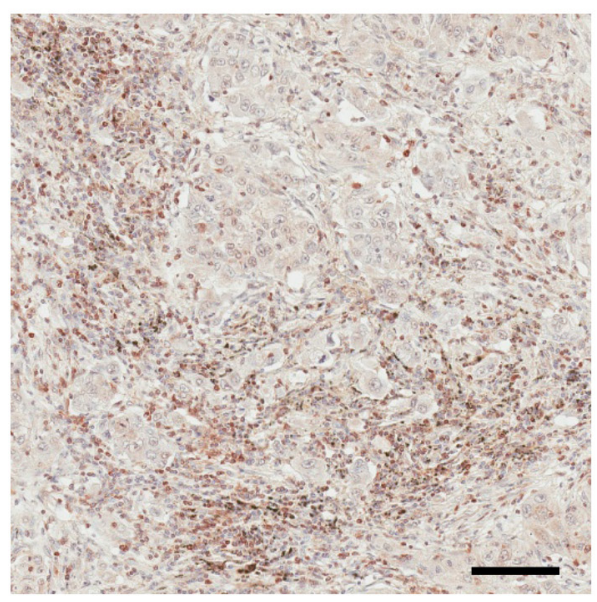

B

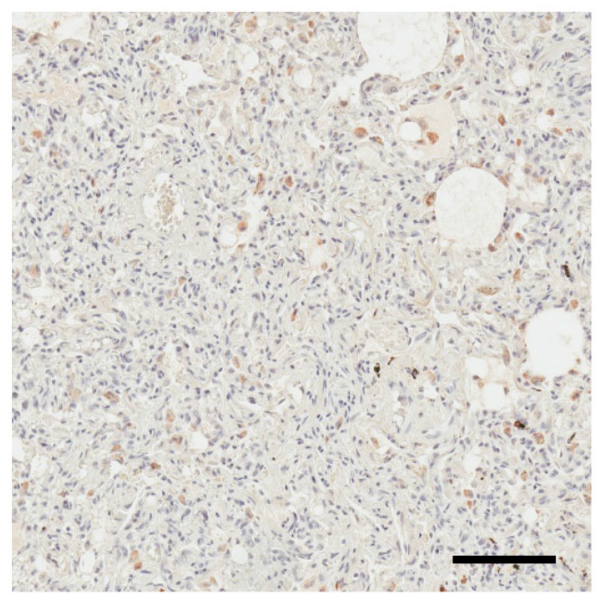

D

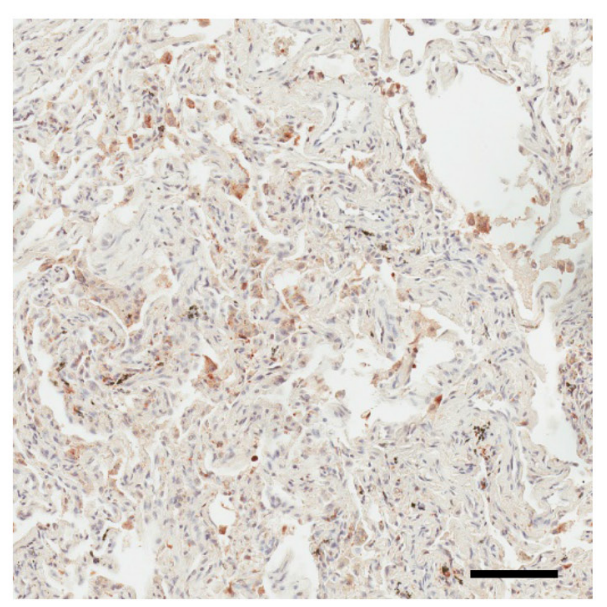

Figure 7: IHC analysis of DC-HIL and ENPP5 in human lung adenocarcinoma and non-cancerous adjacent tissue. (A) Positive DC-HIL staining in stroma of human lung adenocarcinoma. (B) Weak or negative DC-HIL staining in adjacent non-tumorous lung tissue. (C) Positive ENPP5 staining in the stroma of human lung adenocarcinoma. (D) Weak or negative CDH17 staining in adjacent non-tumorous lung tissue. Bar $=100 \mu \mathrm{m}$. 
the present TCSG platform, maps were generated of 210 putative mouse-derived targets unique to the tumor stroma and 109 putative targets unique to the human-derived parenchyma. A total of 93 orthologs were found significantly dysregulated in both tumor compartments. Maps can be used as a source to refine current protein-protein interaction networks in metastatic lung adenocarcinoma. An evidencebased discovery of novel drug targets in these two codependent tumor compartments may also be facilitated by TCSG-generated maps.

The translational relevance of the TCSG approach was shown by cross-validating results of IHC analyses probing parenchymal (CD147, cadherin-17) and stromal targets (DC-HIL, NPP-5). This was performed using human lung adenocarcinoma and normal adjacent tissue. This suggests that the TCSG approach may be used in the initial discovery of putative lung adenocarcinoma biomarkers and/or drug targets. A limited number of clinical specimens represents a weakness of this investigation, precluding more conclusive findings. However, a recent report investigating the expression of CD147 in a total of 1,605 NSCLC patients, showed that the CD147 upregulation was positively associated with aggressive metastatic disease and shorter overall survival [65]. Nevertheless, this work is a sound proof-of-principle investigation that suggests the TCSG platform has significant translational value.

In summary, the results of this investigation authenticate the utility of the TCSG approach for facile and precise dissection of tumor stroma from tumor parenchyma in murine xenografts at a molecular specificity level previously unattainable by other means, with no need for laser-based microdissection. Illustrated here is a powerful tool that can lead to an improved understanding of cancer biology and immunity as well as the discovery of next generation antibodies aiming simultaneously and precisely at targets in tumor parenchyma and tumor stroma. Overall, the present pipeline may be employed as a robust technology in: i) drug and diagnostic target discovery, ii) therapeutic monitoring in the context of cancer immunotherapy, and iii) biology of KRas-driven cancers $[66,67]$. As a complementary resource, the TCSG map/atlas described in this study can be used along with the cancer genome atlas (TCGA) to bioinformatically interrogate the tumor microenvironment and obtain an integrated view of a living tumor using the advantage of an experimental manipulation that is inaccessible in clinical settings. It is even more important in light of a recent study showing the comparative advantage of human cancer cell line models over patient-derived tumor xenograft models [68].

\section{MATERIALS AND METHODS}

\section{Materials}

Hydrazide-terminated $5 \mu \mathrm{m}$ magnetic beads were purchased from Bioclone Inc. (San Diego, CA). Non- ionic Acid Labile Surfactant I (NALS I) was obtained from Protea Biosciences Group (Morgantown, WV). Tris 2-carboxyethylphosphine, Bond Breaker ${ }^{\mathrm{TM}}$ (TCEP) and iodoacetamide (IAA) were obtained from Pierce (Rockford, IL). Sequence-grade modified trypsin was obtained from Promega (Madison, WI). PNGase F was obtained from New England BioLabs (Ipswich, MA). The antibodies used for western blot and immunofluorescence analyses were from the following sources: anti-BSG was from OriGene Technologies (Rockville, MD); all other chemicals were purchased from Sigma-Aldrich (St. Louis, MO). A human lung adenocarcinoma-bearing KRas mutant and the corresponding normal adjacent tissue were obtained from an anonymous donor in the form of formalin-fixed paraffin-embedded (FFPE) tissue blocks, which were purchased from ProteoGenex, Inc. (Culver City, CA) and were accompanied by a pathologist report.

\section{In silico dissimilarity rate analysis}

The tool getfrag.f was built and used to find all tryptic fragments between six and 35AAs for each protein with and without $\mathrm{NxS} \mid \mathrm{T}$ motifs. For uniprot Human.fasta, the files become Human frag noNxST.txt and Human frag NxST.txt, and for uniprot Mouse.fasta, the files become Mouse frag noNxST.txt and Mouse frag NxST.txt. Each of these four files are imported into Excel and sorted by fragment. The number of total fragments between six and 35 amino acids are retained. The program fraguniq. $f$ is then used to identify unique fragments and the protein(s) they belong to. The program/tool compfrag.f was built and used to compare the fragments.

\section{Cell culture}

The A549 human lung adenocarcinoma cell line was purchased from A.T.C.C. (Manassas, VA) and was cultured and passaged in medium containing $10 \%$ fetal bovine serum in a cell culture incubator at $37^{\circ} \mathrm{C}$ in $5 \%$ $\mathrm{CO}_{2}$-saturated humidity conditions.

\section{Mouse xenografts}

Mouse experiments were performed at FNLCR's Laboratory Animal Sciences Program (LASP) in accordance with regulations from the Animal Care and Use Committee and the guidelines of the Animal Welfare Act. The metastatic lung adenocarcinoma mouse model was generated as previously described [28]. Briefly, a total of $20 \mathrm{SCID} / \mathrm{NCr}$ female mice (BALB/C background) at five weeks of age were randomly separated into two groups, experimental and control, $\mathrm{n}=15$ per group. Each mouse in the experimental group was injected with 100 $\mu \mathrm{L}$ of SF medium containing $1 \times 10^{6} 2 \mathrm{D}$-grown A549 cells through the tail vein. Each mouse in the control group was injected with $100 \mu \mathrm{L}$ of SF medium. Tumor generation/ growth in the experimental group was monitored via 
a serial magnetic resonance imaging (MRI) procedure using dual MRI mouse coils. Mice in the experimental group were euthanized upon reaching their endpoint and/ or when their tumors reached a diameter $\geq 5 \mathrm{~mm}$. Tumors were dissected and immediately snap-frozen in liquid nitrogen until further analysis. Correspondingly, mice in the control group were sacrificed at the same time, and the lungs were excised and snap-frozen in liquid nitrogen until further analysis. From each mouse, H\&E stained FFPE tissue sections were prepared and analyzed by a LASP pathologist.

\section{TCSG sample preparation}

Tissue samples were prepared using tip sonication to homogenize $8 \mu \mathrm{m}$-thick tissue slices suspended in a lysis buffer (i.e., $25 \mathrm{mM}$ ammonium bicarbonate containing $1 \mathrm{mM}$ PMSF) as previously described [29], followed by isolation of the crude microsomal fraction. Correspondingly, 2D-grown A549 cells were disrupted in the same lysis buffer using tip sonication, followed by isolation of the microsomal fraction as previously described [69]. The BCA assay was carried out to estimate the protein concentration in the microsomal fraction and was re-suspended in $25 \mathrm{mM}$ ammonium bicarbonate using sonication. A total of $1 \mathrm{mg}$ of protein was aliquoted and solubilized in $0.5 \%$ NALS I followed by sample heating at $95^{\circ} \mathrm{C}$ for 5 minutes. After cooling the sample, a twostep tryptic digestion was performed. In the first step, methanol was added to achieve a $10 \%$ concentration followed by a first spike of Trypsin using a 1:100 enzymeto-substrate ratio, which was followed by incubation at $37^{\circ} \mathrm{C}$ for 2 hours. In the second step, additional methanol was added to achieve a $60 \%$ concentration, and a second spike of Trypsin was added to achieve a 1:50 enzyme-tosubstrate ratio for an overnight digestion. Next, the digest was acidified using 20\% TFA to achieve a $\mathrm{pH}$ level of 2 followed by incubation for 30 minutes at $37^{\circ} \mathrm{C}$ to cleave off NALS I. Following the incubation at $95^{\circ} \mathrm{C}$ for 5 minutes to inactivate trypsin, the digest was centrifuged at $10,000 \mathrm{x} \mathrm{g}$ for 5 minutes, and the supernatant was collected and lyophilized to dryness.

Next, N-glycosylated peptides were captured using a slightly modified approach that was previously described [24], which employs hydrazide-coated magnetic beads at the peptide level instead of hydrazide resin/slurry at the protein level. Briefly, the digest was resuspended in $0.1 \%$ TFA pH 5, which contained $10 \mathrm{mM}$ of sodium periodate and was oxidized for 1 hour at $4^{\circ} \mathrm{C}$. Sodium periodate was removed using a $\mathrm{C} 18$ cartridge, and the peptides were directly eluted into a vial containing hydrazide-coated magnetic beads. Glycopeptides were then conjugated to hydrazide beads by an overnight incubation at $37^{\circ} \mathrm{C}$. In the next step, unconjugated peptides were removed using a series of washes with $1.5 \mathrm{M}$ sodium chloride and $80 \%$ acetonitrile. Finally, N-glycopeptides were released from the magnetic beads by PNGase F during an overnight incubation at $37^{\circ} \mathrm{C}$, and they were desalted using a $\mathrm{C} 18$ column and ultimately stored for LC-MS analysis.

\section{LC-MS and bioinformatic analysis}

Hydrazide-captured/enriched N-glycopeptides were analyzed using nano-flow reversed phase (RP) LC-MS on the Agilent 1100 nano-flow LC system coupled on-line to an Orbitrap Elite mass spectrometer (ThermoElectron, San Jose, CA). The final N-glycopeptide mixture was reconstituted in a total of $20 \mu \mathrm{L}$ of $0.1 \%$ TFA, which was followed by three $5 \mu \mathrm{L}$ injections on a RP column $(75 \mu \mathrm{m}$ i.d. $\times 10 \mathrm{~cm}$ fused silica capillary with a flamepulled tip). Finally, the mixture was slurry-packed inhouse with $5 \mu \mathrm{m}$ of $300 \AA$ pore size C-18 stationary phase (Phenomenex, Torrance, CA). Peptides were eluted from the column using a linear gradient of $2 \%$ mobile phase $\mathrm{B}(0.1 \%$ formic acid in $\mathrm{ACN})$ to $40 \%$ solvent $\mathrm{B}$ for 100 minutes at a flow rate of $0.25 \mu \mathrm{L} / \mathrm{min}$, then to $98 \% \mathrm{~B}$ for an additional 20 minutes. The instrument was operated in a data-dependent mode using the peptide ion mass-to-charge range of 350-1800 and was monitored at the resolution level of 60,000 at m/z 400. Each $\mathrm{MS}^{1}$ scan was followed by $16 \mathrm{MS}^{2}$ scans, wherein the 16 most abundant precursor ions were dynamically selected for collision-induced dissociation using a normalized collision energy of 35\%.

Raw data obtained from the tumor xenograft were analyzed using Proteome Discoverer 1.4 (Thermo) by employing searches against the non-redundant human and mouse proteome database (SwisProt release v57.15). Raw data obtained from the normal mouse lungs and 2D-grown A549 cells were searched against the mouse and human proteome database, respectively. The following thresholds were set: for the monoisotopic peptide precursor ions ( $\mathrm{MS}^{1}$ spectra), mass tolerance was set at $5 \mathrm{ppm}$, and for the fragment ions (data-dependent $\mathrm{MS}^{2}$ spectra), mass tolerance was set at 0.6 Da. Dynamic amino acid modifications were added for the detection of the following: $+0.984 \mathrm{Da}$ for asparagine deamidation (i.e., deamidation of N-glycosylated asparagines via PNGase $F$ treatment), +57.021 Da for cysteine carboxyamidomethylation (i.e., alkylation), and +15.994 Da for methionine oxidation. Peptides with one tryptic terminus $(\mathrm{K}, \mathrm{R})$ meeting these thresholds were considered legitimate identifications. Finally, search results were filtered for the presence of peptides containing deamidated asparagine in the context of the $\mathrm{N}$-glycosylation sequence motif (i.e., NxST) to further decrease the peptide/protein false discovery rate (FDR). N-glycosylated proteins identified by a single peptide spectrum match (PSM) were not included in the final dataset. Protein grouping was employed to increase the quality and reliability of the protein identifications and to enforce economy in the number of identified proteins. N-glycosylated proteins were characterized in accordance with their annotations in 
the human cell surface protein atlas (CSPA). Selection and prioritization of cell-surface proteins for antibody-based cross-validation using IHC, IF, and WB analyses were facilitated using PANTHER and IPA ${ }^{\circledR}$ bioinformatic tools. Raw MS data is accessible at the https://vmsshare.nist.gov.

\section{Statistical analysis}

Spectral counting-based relative quantitation of the changes in $\mathrm{N}$-glycosylated protein regulation between the tumor parenchyma and tumor stroma was carried out using PSMs readouts, which were computed by the Percolator algorithm within Proteome Discoverer 1.4. Percolator relies on semi-supervised machine learning to improve the discrimination between correct and incorrect spectra identifications by considering $p$-value, q-value, and posterior error probability for each peptide match at the selected strict FDR of $\leq 0.01$. Significant differences in protein regulation were estimated using binomial probability and false discovery rate (FDR) calculations [70].

\section{Generation of the non-redundant cell surface map of tumor parenchyma and tumor stroma}

Subtractive proteomic analysis was used to reveal the non-redundant list of human-derived targets identified solely in tumor parenchyma and the mouse-derived targets identified in tumor stroma, respectively. Comparative proteomic analysis that relies on spectral counting to quantify relative changes in protein abundances was used to reveal a non-redundant list of proteins differently regulated between the tumor parenchyma and tumor stroma.

\section{IHC analysis}

The $6 \mu \mathrm{m}$-thick paraffin-embedded sections of FFPE tissue were dewaxed in three changes of xylene ( 5 minutes each), hydrated in decreasing concentrations of ethanol $(100 \%, 95 \%$, and $70 \%)$, and washed in water. For antigen retrieval, slides submerged in retrieval buffer (Dako, Santa Clara, CA) were heated in a steamer for 15 minutes followed by cooling at room temperature for 15 minutes. Tissue sections were immunostained with primary antibody followed by HRP conjugated polymer secondary antibody amplification kit (DAKO) and DAB substrate. Tissue sections were then counterstained with hematoxylin, dehydrated, and mounted with cover slips. Omission of the primary antibody served as a negative control. Images of stained tissues were obtained by scanning slides with the ScanScope XT digital slide scanner (Aperio Technologies, Inc., Vista, California) and viewed with the ImageScope program (Aperio Technologies, Inc.). The human MHC-I, CD44, and EPNN5 antibodies are from Abcam (Cambridge,
MA); human CD147 is from Cell Signaling Technologies (Danvers, MA); GPNMB is from R\&D Systems (Minneapolis, MN), and Cadherin 17 is from Sigma (St. Louis, MO).

\section{IF analysis}

A549 cells were cultured on coverslips and washed with cold PBS three times, fixed in 4\% formaldehyde, permeabilized with $0.1 \%$ Triton $\mathrm{X}-100$, and blocked with Odyssey $^{\text {TM }}$ Blocking Buffer (Li-Cor, Cambridge, UK) for 1 hour. Cells were then incubated with primary antibodies overnight at $4^{\circ} \mathrm{C}$, followed by incubation with Alexa Fluor 594 conjugated secondary antibodies and phalloidin-FITC (Invitrogen) for 2 hours. Cells were also stained with 4,6-diamidino-2-phenylindole (DAPI) (Invitrogen) to visualize the nuclei.

\section{Fluorescent microscopy}

Wide-field images were acquired on a Nikon Eclipse Ti inverted microscope using a 60x NA 1.42 Plan Apo objective. The microscope was equipped with a 64 $\mu \mathrm{m}$ pixel CoolSNAP $\mathrm{HQ}^{2}$ camera (Photometrics) and Intensilight C-HGFIE illuminator, and $200 \mathrm{~nm}$ Z-sections were acquired. ImageJ (National Institutes of Health, Bethesda, MD) software was used to make maximum intensity projections and to assemble figures. Structured illumination microscopy (SIM) that relies on a grid pattern to provide higher resolution images was performed on an N-SIM (Nikon Inc.) equipped with an Apo TIRF 100x NA 1.49 Plan Apo oil objective and 405, 488, 561, and $640 \mathrm{~nm}$ excitation lasers as well as a back-illuminated $16 \mu \mathrm{m}$ pixel EMCCD camera (Andor, DU897). 100 nm Z-sections were acquired in 3D SIM mode, generating 15 images per plane. Channels were corrected for chromatic shift based on the signals of $100 \mathrm{~nm}$ multi-spectral fluorescent spheres (TetraSpeck beads, Invitrogen) that were included in the mounting medium. For 3D visualization, we used the NISelements software package. To allow for comparison of the signal intensities, cells were imaged using identical imaging settings, and the images were processed identically during figure assembly.

\section{CONFLICTS OF INTEREST}

The authors declare that they have no conflicts of interest.

\section{FUNDING}

This project has been funded in whole or in part with Federal funds from the National Cancer Institute, National Institutes of Health, under Contract No. HHSN261200800001E. The content of this publication does not necessarily reflect the views or policies of 
the Department of Health and Human Services, nor does mention of trade names, commercial products, or organizations imply endorsement by the U.S. Government.

\section{REFERENCES}

1. Niu N, Wang L. In vitro human cell line models to predict clinical response to anticancer drugs. Pharmacogenomics. 2015; 16:273-85. https://doi.org/10.2217/pgs.14.170.

2. Katt ME, Placone AL, Wong AD, Xu ZS, Searson PC. In vitro tumor models: advantages, disadvantages, variables, and selecting the right platform. Front Bioeng Biotechnol. 2016; 4:12. https://doi.org/10.3389/fbioe.2016.00012.

3. Cekanova M, Rathore K. Animal models and therapeutic molecular targets of cancer: utility and limitations. Drug Des Devel Ther. 2014; 8:1911-21. https://doi.org/10.2147/ DDDT.S49584.

4. Zalatnai A. Molecular aspects of stromal-parenchymal interactions in malignant neoplasms. Curr Mol Med. 2006; 6:685-93.

5. Brennen WN, Rosen DM, Wang H, Isaacs JT, Denmeade SR. Targeting carcinoma-associated fibroblasts within the tumor stroma with a fibroblast activation protein-activated prodrug. Journal of the National Cancer Institute. 2012; 104:1320-34.

6. Sivridis E, Giatromanolaki A, Koukourakis MI. "Stromatogenesis" and tumor progression. Int J Surg Pathol. 2004; 12:1-9. https://doi.org/10.1177/106689690401200101.

7. Folkman J, Shing Y. Angiogenesis. J Biol Chem. 1992; 267:10931-4

8. Demetri GD. Identification and treatment of chemoresistant inoperable or metastatic GIST: experience with the selective tyrosine kinase inhibitor imatinib mesylate (STI571). Eur J Cancer. 2002; 38:S52-9.

9. Ross J, Gray K, Schenkein D, Greene B, Gray GS, Shulok J, Worland PJ, Celniker A, Rolfe M. Antibody-based therapeutics in oncology. Expert Rev Anticancer Ther. 2003; 3:107-21. https://doi. org/10.1586/14737140.3.1.107.

10. Ahmed F, Steele JC, Herbert JMJ, Steven NM, Bicknell R. Tumor Stroma as a Target in Cancer. Current Cancer Drug Targets. 2008; 8:447-53. https://doi. org/10.2174/156800908785699360.

11. Giesen C, Wang HA, Schapiro D, Zivanovic N, Jacobs A, Hattendorf B, Schuffler PJ, Grolimund D, Buhmann JM, Brandt S, Varga Z, Wild PJ, Gunther D, et al. Highly multiplexed imaging of tumor tissues with subcellular resolution by mass cytometry. Nat Methods. 2014; 11:41722. https://doi.org/10.1038/nmeth.2869.

12. Angelo M, Bendall SC, Finck R, Hale MB, Hitzman C, Borowsky AD, Levenson RM, Lowe JB, Liu SD, Zhao S, Natkunam Y, Nolan GP. Multiplexed ion beam imaging of human breast tumors. Nat Med. 2014; 20:436-42. https:// doi.org/10.1038/nm.3488.
13. Hoffman RM, Bouvet M. Imaging the microenvironment of pancreatic cancer patient-derived orthotopic xenografts (PDOX) growing in transgenic nude mice expressing GFP, RFP, or CFP. Cancer Lett. 2016; 380:349-55. https://doi. org/10.1016/j.canlet.2015.12.021.

14. Emmert-Buck MR, Bonner RF, Smith PD, Chuaqui RF, Zhuang Z, Goldstein SR, Weiss RA, Liotta LA. Laser capture microdissection. Science. 1996; 274:998-1001.

15. Espina V, Wulfkuhle JD, Calvert VS, VanMeter A, Zhou WD, Coukos G, Geho DH, Petricoin EF, Liotta LA. Laser-capture microdissection. Nature Protocols. 2006; 1:586-603.

16. Hembrough T, Thyparambil S, Liao WL, Darfler MM, Abdo J, Bengali KM, Taylor P, Tong J, Lara-Guerra H, Waddell TK, Moran MF, Tsao MS, Krizman DB, et al. Selected reaction monitoring (SRM) analysis of epidermal growth factor receptor (EGFR) in formalin fixed tumor tissue. Clin Proteomics. 2012; 9:5. https://doi. org/10.1186/1559-0275-9-5.

17. Johann DJ, Rodriguez-Canales J, Mukherjee S, Prieto DA, Hanson JC, Emmert-Buck M, Blonder J. Approaching solid tumor heterogeneity on a cellular basis by tissue proteomics using laser capture microdissection and biological mass spectrometry. J Proteome Res. 2009; 8:2310-8. https://doi. org/10.1021/pr8009403.

18. Staunton L, Tonry C, Lis R, Espina V, Liotta L, Inzitari R, Bowden M, Fabre A, O'Leary J, Finn SP, Loda M, Pennington SR. Pathology-driven comprehensive proteomic profiling of the prostate cancer tumor microenvironment. Mol Cancer Res. 2017; 15:281-93. https://doi. org/10.1158/1541-7786.MCR-16-0358.

19. Timms JF, Hale OJ, Cramer R. Advances in mass spectrometry-based cancer research and analysis: from cancer proteomics to clinical diagnostics. Expert Rev Proteomics. 2016; 13:593-607. https://doi.org/10.1080/147 89450.2016.1182431.

20. Jensen EC. Laser capture microdissection. Anat Rec A Discov Mol Cell Evol Biol. 2013; 296:1683-7.

21. Tang HY, Beer LA, Chang-Wong T, Hammond R, Gimotty P, Coukos G, Speicher DW. A xenograft mouse model coupled with in-depth plasma proteome analysis facilitates identification of novel serum biomarkers for human ovarian cancer. Journal of Proteome Research. 2012; 11:678-91.

22. Wang X, Mooradian AD, Erdmann-Gilmore P, Zhang Q, Viner R, Davies SR, Huang KL, Bomgarden R, Van Tine BA, Shao J, Ding L, Li S, Ellis MJ, et al. Breast tumors educate the proteome of stromal tissue in an individualized but coordinated manner. Sci Signal. 2017; 10. https://doi. org/10.1126/scisignal.aam8065.

23. Habermann B, Oegema J, Sunyaev S, Shevchenko A. The power and the limitations of cross-species protein identification by mass spectrometry-driven sequence similarity searches. Molecular \& Cellular Proteomics. 2004; 3:238-49. 
24. Zhang H, Li XJ, Martin DB, Aebersold R. Identification and quantification of N-linked glycoproteins using hydrazide chemistry, stable isotope labeling and mass spectrometry. Nature Biotechnology. 2003; 21:660-6.

25. Lindner D. Animal models and the tumor microenvironment: studies of tumor-host symbiosis. Semin Oncol. 2014; 41:146-55. https://doi.org/10.1053/j. seminoncol.2014.02.004.

26. Pinho SS, Reis CA. Glycosylation in cancer: mechanisms and clinical implications. Nat Rev Cancer. 2015; 15:540-55. https://doi.org/10.1038/nrc3982.

27. Rudd PM, Elliott T, Cresswell P, Wilson IA, Dwek RA. Glycosylation and the immune system. Science. 2001; 291:2370-6.

28. Wei QO, Jiang H, Xiao Z, Baker A, Young MR, Veenstra TD, Colburn NH. Sulfiredoxin-Peroxiredoxin IV axis promotes human lung cancer progression through modulation of specific phosphokinase signaling. Proceedings of the National Academy of Sciences of the United States of America. 2011; 108:7004-9.

29. Prieto DA, Chan KC, Johann DJ Jr, Ye X, Whitely G, Blonder J. Preparation and immunoaffinity depletion of fresh frozen tissue homogenates for mass spectrometrybased proteomics in the context of drug target/biomarker discovery. Methods Mol Biol. 2017; 1647:71-90. https://doi. org/10.1007/978-1-4939-7201-2_5.

30. Ye X, Johann DJ Jr, Hakami RM, Xiao Z, Meng Z, Ulrich RG, Issaq HJ, Veenstra TD, Blonder J. Optimization of protein solubilization for the analysis of the CD14 human monocyte membrane proteome using LC-MS/MS. J Proteomics. 2009; 73:112-22. https://doi.org/10.1016/j. jprot.2009.08.008.

31. Tian YA, Zhou Y, Elliott S, Aebersold R, Zhang H. Solidphase extraction of N-linked glycopeptides. Nature Protocols. 2007; 2:334-9.

32. Bausch-Fluck D, Hofmann A, Bock T, Frei AP, Cerciello F, Jacobs A, Moest H, Omasit U, Gundry RL, Yoon C, Schiess R, Schmidt A, Mirkowska P, et al. A mass spectrometricderived cell surface protein atlas. PloS One. 2015; 10. https://doi.org/10.1371/journal.pone.0121314.

33. Engel P, Boumsell L, Balderas R, Bensussan A, Gattei V, Horejsi V, Jin BQ, Malavasi F, Mortari F, SchwartzAlbiez R, Stockinger H, van Zelm MC, Zola H, et al. CD nomenclature 2015: human leukocyte differentiation antigen workshops as a driving force in immunology. J Immunol. 2015; 195:4555-63. https://doi.org/10.4049/ jimmunol.1502033.

34. Carvalho PC, Hewel J, Barbosa VC, Yates JR 3rd. Identifying differences in protein expression levels by spectral counting and feature selection. Genet Mol Res. 2008; 7:342-56.

35. Johann DJ Jr, Wei BR, Prieto DA, Chan KC, Ye X, Valera VA, Simpson RM, Rudnick PA, Xiao Z, Issaq HJ, Linehan WM, Stein SE, Veenstra TD, et al. Combined blood/tissue analysis for cancer biomarker discovery: application to renal cell carcinoma. Anal Chem. 2010; 82:1584-8. https:// doi.org/10.1021/ac902204k.

36. Panico F, Casali C, Rossi G, Rizzi F, Morandi U, Bettuzzi S, Davalli P, Corbetta L, Storelli ES, Corti A, Fabbri LM, Astancolle S, Luppi F. Prognostic role of clusterin in resected adenocarcinomas of the lung. Lung Cancer. 2013; 79:294-9. https://doi.org/10.1016/j.lungcan.2012.11.024.

37. Zheng WQ, Jiang CH, Li RF. Integrin and gene network analysis reveals that ITGA5 and ITGB1 are prognostic in non-small-cell lung cancer. Onco Targets Ther. 2016; 9. https://doi.org/10.2147/Ott.S91796.

38. Ye X, Chan KC, Waters AM, Bess M, Harned A, Wei BR, Loncarek J, Luke BT, Orsburn BC, Hollinger BD, Stephens RM, Bagni R, Martinko A, et al. Comparative proteomics of a model MCF10A-KRasG12V cell line reveals a distinct molecular signature of the KRasG12V cell surface. Oncotarget. 2016; 7:86948-71. https://doi.org/10.18632/ oncotarget. 13566.

39. Muramatsu T. Basigin (CD147), a multifunctional transmembrane glycoprotein with various binding partners. Journal of Biochemistry. 2016; 159:481-90. https://doi. org/10.1093/jb/mvv127.

40. Kendrick AA, Schafer J, Dzieciatkowska M, Nemkov T, D'Alessandro A, Neelakantan D, Ford HL, Pearson CG, Weekes CD, Hansen KC, Eisenmesser EZ. CD147: a small molecule transporter ancillary protein at the crossroad of multiple hallmarks of cancer and metabolic reprogramming. Oncotarget. 2017; 8:6742-62. https://doi.org/10.18632/ oncotarget.14272.

41. Zhao P, Damerow MS, Stern P, Liu AH, Sweet-Cordero A, Siziopikou K, Neilson JR, Sharp PA, Cheng C. CD44 promotes Kras-dependent lung adenocarcinoma. Oncogene. 2013; 32:5186-90. https://doi.org/10.1038/ onc.2012.542.

42. Elkin SR, Bendris N, Reis CR, Zhou YY, Xie Y, Huffman KE, Minna JD, Schmid SL. A Systematic Analysis Reveals Heterogeneous Changes in the Endocytic Activities of Cancer Cells. Cancer Research. 2015; 75:4640-50. https:// doi.org/10.1158/0008-5472.Can-15-0939.

43. Guo CY, Yan C, Luo L, Goto S, Urata Y, Xu JJ, Wen XM, Kuang YK, Tou FF, Li TS. Enhanced expression of PKM2 associates with the biological properties of cancer stem cells from A549 human lung cancer cells. Oncol Rep. 2017; 37:2161-6. https://doi.org/10.3892/or.2017.5438.

44. Pinheiro C, Reis RM, Ricardo S, Longatto-Filho A, Schmitt F, Baltazar F. Expression of monocarboxylate transporters 1, 2, and 4 in human tumours and their association with CD147 and CD44. J Biomed Biotechnol. 2010; 2010:427694. https://doi.org/10.1155/2010/427694.

45. Takamura M, Yamagiwa S, Matsuda Y, Ichida T, Aoyagi Y. Involvement of liver-intestine cadherin in cancer progression. Med Mol Morphol. 2013; 46:1-7. https://doi. org/10.1007/s00795-012-0003-y. 
46. Goswami KK, Ghosh T, Ghosh S, Sarkar M, Bose A, Baral R. Tumor promoting role of anti-tumor macrophages in tumor microenvironment. Cell Immunol. 2017; 316:1-10. https://doi.org/10.1016/j.cellimm.2017.04.005.

47. Nazareth MR, Broderick L, Simpson-Abelson MR, Kelleher RJ, Yokota SJ, Bankert RB. Characterization of human lung tumor-associated fibroblasts and their ability to modulate the activation of tumor-associllited T cells. The Journal of Immunology. 2007; 178:5552-62.

48. Yearley JH, Gibson C, Yu N, Moon C, Murphy E, Juco J, Lunceford J, Cheng J, Chow LQM, Seiwert TY, Handa M, Tomassini JE, McClanahan T. PD-L2 expression in human tumors: relevance to anti-PD-1 therapy in cancer. Clin Cancer Res. 2017; 23:3158-67. https://doi. org/10.1158/1078-0432.CCR-16-1761.

49. Fridlender ZG, Sun J, Mishalian I, Singhal S, Cheng GJ, Kapoor V, Horng W, Fridlender G, Bayuh R, Worthen GS, Albelda SM. Transcriptomic analysis comparing tumorassociated neutrophils with granulocytic myeloid-derived suppressor cells and normal neutrophils. PLoS One. 2012; 7.

50. Gonzalez-Chavarria I, Cerro RP, Parra NP, Sandoval FA, Zuniga FA, Omazabal VA, Lamperti LI, Jimenez SP, Fernandez EA, Gutierrez NA, Rodriguez FS, Onate SA, Sanchez O, et al. Lectin-like oxidized LDL receptor-1 is an enhancer of tumor angiogenesis in human prostate cancer cells. PloS One. 2014; 9. https://doi.org/10.1371/journal. pone.0106219.

51. Kong LM, Liao CG, Fei F, Guo X, Xing JL, Chen ZN. Transcription factor $\mathrm{Sp} 1$ regulates expression of cancerassociated molecule CD147 in human lung cancer. Cancer Science. 2010; 101:1463-70.

52. Bartolome RA, Barderas R, Torres S, Fernandez-Acenero MJ, Mendes M, Garcia-Foncillas J, Lopez-Lucendo M, Casal JI. Cadherin-17 interacts with alpha2beta1 integrin to regulate cell proliferation and adhesion in colorectal cancer cells causing liver metastasis. Oncogene. 2014; 33:1658-69. https://doi.org/10.1038/onc.2013.117.

53. Buccheri G, Torchio P, Ferrigno D. Clinical equivalence of two cytokeratin markers in non-small cell lung cancer - A study of tissue polypeptide antigen and cytokeratin 19 fragments. Chest. 2003; 124:622-32.

54. Rose AAN, Biondini M, Curiel R, Siegel PM. Targeting GPNMB with glembatumumab vedotin: current developments and future opportunities for the treatment of cancer. Pharmacol Ther. 2017; 179:127-41. https://doi. org/10.1016/j.pharmthera.2017.05.010.

55. Chung JS, Sato K, Dougherty II, Cruz PD, Ariizumi K. DC-HIL is a negative regulator of T lymphocyte activation. Blood. 2007; 109:4320-7.

56. Goding JW, Grobben B, Slegers H. Physiological and pathophysiological functions of the ecto-nucleotide pyrophosphatase/phosphodiesterase family. Biochim Biophys Acta. 2003; 1638:1-19. https://doi.org/10.1016/ S0925-4439(03)00058-9.
57. Smith SJ, Tilly H, Ward JH, Macarthur DC, Lowe J, Coyle B, Grundy RG. CD105 (Endoglin) exerts prognostic effects via its role in the microvascular niche of paediatric high grade glioma. Acta Neuropathol. 2012; 124:99-110. https:// doi.org/10.1007/s00401-012-0952-1.

58. Adler MJ, Dimitrov DS. Therapeutic antibodies against cancer. Hematol Oncol Clin North Am. 2012; 26:447-81, vii. https://doi.org/10.1016/j.hoc.2012.02.013.

59. Al-Abd AM, Alamoudi AJ, Abdel-Naim AB, Neamatallah TA, Ashour OM. Anti-angiogenic agents for the treatment of solid tumors: potential pathways, therapy and current strategies - a review. J Adv Res. 2017; 8:591-605. https:// doi.org/10.1016/j.jare.2017.06.006.

60. De Palma M, Biziato D, Petrova TV. Microenvironmental regulation of tumour angiogenesis. Nat Rev Cancer. 2017; 17:457-74. https://doi.org/10.1038/nrc.2017.51.

61. Martinko AJ, Truillet C, Julien O, Diaz JE, Horlbeck MA, Whiteley G, Blonder J, Weissman JS, Bandyopadhyay S, Evans MJ, Wells JA. Targeting RAS-driven human cancer cells with antibodies to upregulated and essential cellsurface proteins. Elife. 2018; 7. https://doi.org/10.7554/ eLife.31098.

62. Blonder J, Terunuma A, Conrads TR, Chan KC, Yee C, Lucas DA, Schaefer CF, Yu LR, Issaq HJ, Veenstra TD, Vogel JC. A proteomic characterization of the plasma membrane of human epidermis by high-throughput mass spectrometry. J Invest Dermatol. 2004; 123:691-9. https:// doi.org/10.1111/j.0022-202X.2004.23421.x.

63. Johann DJ, Mukherjee S, Prieto DA, Veenstra TD, Blonder J. Profiling solid tumor heterogeneity by LCM and biological MS of fresh-frozen tissue sections. Methods Mol Biol. 2011; 755:95-106. https://doi. org/10.1007/978-1-61779-163-5_8.

64. Wei BR, Simpson RM, Johann DJ, Dwyer JE, Prieto DA, Kumar M, Ye X, Luke B, Shive HR, Webster JD, Hoover $\mathrm{SB}$, Veenstra TD, Blonder J. Proteomic profiling of H-Ras$\mathrm{G} 12 \mathrm{~V}$ induced hypertrophic cardiomyopathy in transgenic mice using comparative LC-MS analysis of thin freshfrozen tissue sections. J Proteome Res. 2012; 11:1561-70. https://doi.org/10.1021/pr200612y.

65. Zhang X, Tian T, Zhang X, Liu C, Fang X. Elevated CD147 expression is associated with shorter overall survival in non-small cell lung cancer. Oncotarget. 2017; 8:37673-80. https://doi.org/10.18632/oncotarget.16948.

66. Li N, Liu S, Sun M, Chen W, Xu X, Zeng Z, Tang Y, Dong Y, Chang AH, Zhao Q. Chimeric antigen receptor-modified T cells redirected to EphA2 for the immunotherapy of nonsmall cell lung cancer. Transl Oncol. 2018; 11:11-7. https:// doi.org/10.1016/j.tranon.2017.10.009.

67. Sakamoto S, Inoue H, Ohba S, Kohda Y, Usami I, Masuda T, Kawada M, Nomoto A. New metastatic model of human small-cell lung cancer by orthotopic transplantation in mice. Cancer Sci. 2015; 106:367-74. https://doi.org/10.1111/ cas. 12624 . 
68. Ben-David U, Ha G, Tseng YY, Greenwald NF, Oh C, Shih J, McFarland JM, Wong B, Boehm JS, Beroukhim R, Golub TR. Patient-derived xenografts undergo mouse-specific tumor evolution. Nat Genet. 2017; 49:1567-75. https://doi. org/10.1038/ng.3967.

69. Blonder J, Rodriguez-Galan MC, Chan KC, Lucas DA, Yu LR, Conrads TP, Issaq HJ, Young HA, Veenstra TD. Analysis of murine natural killer cell microsomal proteins using two-dimensional liquid chromatography coupled to tandem electrospray ionization mass spectrometry. Journal of Proteome Research. 2004; 3:862-70. https://doi. org/10.1021/pr049927e.

70. Benjamini Y, Hochberg Y. Controlling the false discovery rate - a practical and powerful approach to multiple testing. J R Stat Soc Ser B. 1995; 57:289-300. 